\title{
Trauer und Angst in Freude und Hoffnung transformieren. Zum Beitrag der Praktischen Theologie im Kontext von Flucht und Migration
}

\author{
Regina Polak
}

Emotions play an eminent role in the current societal and political debates about flight and migration. Framed by racist and right-wing populist politics, these emotions become threatening factors within the search for solutions of the so called refugee-crisis since summer 2015. At the same time one can find an overwhelming engagement for refugees in civil society.

The article asks for the contribution of practical theology in this context. The importance of "the joys and the hopes, the griefs and the anxieties of the men of this age" (GS 1), the Second Vaticanum gives to these moods is the starting point of an interdisciplinary reflection, what could be the practical and theoretical benefit of a theological intellectuality asking for ways to transform human emotions into spiritual moods, attitudes and ethics. By referring to results of social science the author paints a multifaceted picture of the challenges in Europe in the context of flight and migration. Afterwards, she discusses aspects of a biblical Theology of migration to show how these could offer new perspectives on perceiving the current historical moment and also find possibilities to act: How can the anxieties of Europeans be transformed into hope by theological thinking? What are the reasons for joys and hopes? And could they have relevance also for a secular society?

Regina Polak, born in 1967, is Associate Professor for Practical Theology at the Catholic Faculty of the University of Vienna. She studied Catholic theology, philosophy and spiritual theology in the interreligious process in Vienna and Salzburg. She is the leader of the network Religion in the Context of Migration and member of the research platform Religion and Transformation in Contemporary Society. She has taught at the University of Szeged (Hungary), the Jagellonian University in Krakau (Poland), the University of Haifa (Israel) and given lectures at St. John's University in New York and Stanford University (USA). Her research foci are religion and migration, transformation of religion in Europe, transformation of the Catholic Church, value research. 


\section{Einleitung}

\subsection{Freude und Hoffnung, Trauer und Angst als geschichtliche Wirkmächte}

Freude und Hoffnung, Trauer und Angst der Menschen von heute, besonders der Armen und Bedrängten aller Art, sind auch Freude und Hoffnung, Trauer und Angst der Jünger Christi. Und es gibt nichts wahrhaft Menschliches, das nicht in ihren Herzen seinen Widerhall fände. (GS 1)

Mit diesen - wohl Millionen Mal zitierten - Worten eröffnen die Konzilsväter des Zweiten Vatikanischen Konzils die Pastoralkonstitution Gaudium et Spes, die das Verhältnis der Kirche zur Welt theologisch revolutioniert. Nach Jahrhunderten eines hierarchischen Gegenübers vollzieht die Kirche einen radikalen Ortswechsel, indem sie sich an die Seite der Menschen mitten in die Welt stellt und bereit zeigt, in den „Zeichen der Zeit“ das Evangelium auf neue Weise zu entdecken. ${ }^{1}$

Es ist bemerkenswert, dass dieser Ortswechsel mit einem Verweis auf Phänomene eröffnet wird, die wir im Westen in der Regel mit Gefühlen assoziieren: Freude, Hoffnung, Trauer, Angst. Aber besteht die Aufgabe der Kirche nunmehr tatsächlich primär im Teilen von Gefühlen? Warum nehmen überhaupt Gefühle einen so zentralen Raum ein?

Mit Blick auf eine, insbesondere biblisch fundierte christliche Spiritualität scheint mir eine solche Deutung reduziert zu sein. Der Eröffnungssatz der Pastoralkonstitution ist alles andere als romantisch, naiv oder gar harmlos; vor allem für die praktisch-theologischen Fächer, die von den konkreten „Zeichen der Zeit“ ausgehen und von diesen her den Glauben als Lebensweise in der Gegenwart theologisch reflektieren und praktisch zu meliorisieren versuchen. ${ }^{2}$ Die Praxis der Gläubigen, die diesem Satz entspringen kann und soll, erschöpft sich keinesfalls in Mitgefühl, so zentral dieses als Ausgangspunkt auch ist. Die Nennung jener vier menschlichen Gefühle hat eine tiefe spirituelle, d.h. intellektuelle, praktische und darin geistliche Bedeutung.

Denn Freude und Hoffnung, Trauer und Angst sind keinesfalls nur Gefühle im Sinne innerer Regungen und Affekte. Vielmehr handelt es sich um geistig-leibliche Grundstimmungen menschlichen Daseins. „In“ solchen Stimmungen finden sich Menschen in der Welt vor und ,in“ ihnen beziehen sie sich auf ihre Mitmenschen, auf ihre Wirklichkeit und Welt, auf Gesellschaft und Geschichte, auf den Kosmos und schließlich auch auf Gott. ${ }^{3}$ Diese Grundstimmungen prägen die

1 Vgl. Sander 2006, S. 434-445. Ders. 1997, S. 85-102.

2 Vgl. Polak 2015a, S. 83-88.

3 Ich beziehe mich hier auf Martin Heidegger, der in seiner „Daseinsanalytik“ in „Sein und Zeit“ darauf hinweist, dass jedes Verstehen und Handeln von bestimmten vorreflexiven „Stimmungen“ begleitet wird, die Verstehensvollzüge begleiten und darin 
Wahrnehmung der Wirklichkeit und drücken sich im Handeln aus. Denken, Fühlen und Handeln als menschliche Fähigkeiten vollziehen sich im Element dieser Grundstimmungen. Freude und Hoffnung, Trauer und Angst sind demnach geistige Wirklichkeiten, d.h. sie stiften Beziehungen zwischen Menschen, Welt und Gott und wirken sich darin leiblich aus: in Gefühlen als leiblicher Reaktion und im Handeln als Ausdruck, die diesen Beziehungen konkrete Gestalt geben. ${ }^{4}$ Als Einstellungen, in denen Menschen der Wirklichkeit begegnen, haben sie maßgeblichen Einfluss auf die Praxis der menschlichen Gemeinschaft.

Das Konzil misst demnach den Stimmungen - den geistigen Beziehungsformen -, in denen sich Menschen vorfinden und in denen die „Jünger Christi“ den Menschen begegnen, eine höchst bedeutsame Schlüsselrolle zu. Vor allem konkreten Urteilen und Handeln der Gläubigen in der Welt wird die Welt auf eine bestimmte geistige Weise wahrgenommen und mit ihr Beziehung aufgenommen. Das „Mit-gefühl“, das hier an den Beginn des Nachdenkens über das Handeln der Kirche in der Welt von heute gestellt wird, geht weit über Emotionalität hinaus: Es beschreibt eine spezifische Beziehungsform des emotionalen, geistigen und praktischen Begleitens und Teilens. Denn geistige Einstellungen sind aus der Sicht christlicher Spiritualität untrennbar verbunden mit der Weise, die Welt zu denken und $\mathrm{zu}$ verstehen, in und mit ihr zu handeln. Die hier benannten Grundstimmungen sind aus der Sicht der Konzilsväter offenbar jene, in denen die Gläubigen der Welt begegnen und die sie in besonderer Weise ernst nehmen sollen.

Es gibt verschiedene Weisen, sich auf die Welt zu beziehen: Neugier, Leidenschaft, Lust, Verzweiflung, Resignation, Optimismus und Pessimismus, Depression und Euphorie, Resignation, Ressentiment oder gar Hass uvm. Aus der Fülle der möglichen Gestimmtheiten wählt das Konzil jedoch diese vier, denen es Macht und Kraft zuschreibt, die Welt zu gestalten. Dabei sollen Freude und Hoffnung wohl das „Gegenprogramm“ des Evangeliums zu Trauer und Angst darstellen. Zugleich wissen die Autoren aber um die Notwendigkeit, dass Trauer und Angst als wirkmächtige Kräfte der Geschichte zuerst benannt und anerkannt

das Handeln leiten, d.h. Verstehen und Handeln eröffnen oder verstellen können. Sie lassen sich nicht aus den konkreten Ereignissen ableiten, sondern hängen mit der Art und Weise zusammen, wie der Mensch sich selbst in der Welt vorfindet und „definiert“. So bekommen sie geschichtliche Bedeutung, vgl. Heidegger 1977, S. 178 ff.; Insofern sich diese vorreflexiven Stimmungen als geistige Einstellungen zur Wirklichkeit reflektieren und daher auch bilden lassen, scheint mir eine große formale Nähe zu christlicher Spiritualität gegeben, da auch diese in all ihrer Pluralität der Zugänge darauf abzielt, die Beziehung zur Wirklichkeit zu transformieren.

4 Ich beziehe mich hier auf Hannah Arendt, die in ihrer Reflexion menschlichen Handelns drei verschiedene Tätigkeitsformen (Arbeit, Herstellen, Handeln) unterschieden hat, denen m. M. allen gemeinsam ist, dass sie die Relationalität des Menschen beschreiben, vgl. Arendt ${ }^{2} 1981$. 
werden müssen, um jene Freude und Hoffnung als Grundmodi der Wirklichkeitsbegegnung entdecken zu können, die das Evangelium als Wege aus Trauer und Angst eröffnet. Die „Erlösung“ auch von Stimmungen setzt die Anerkennung der tatsächlichen Gestimmtheiten voraus. ${ }^{5}$ Aber Trauer und Angst kommen eben nicht an erster Stelle, sie haben nicht das letzte Wort. Freude und Hoffnung haben Vorrang.

Freilich, Freude und Hoffnung kann man nicht per Konzilsdekret verordnen. Sie müssen verstanden, gelernt und eingeübt werden, sollen sie über das bloße Gefühl hinausgehen und dem menschlichen Geist Orientierung für das Handeln geben. Man könnte daher auch von Habitus sprechen: Tugenden, zu denen diese Beziehungsformen „geronnen“ sein müssen, damit die Gläubigen ihrem Auftrag in der Welt angemessen nachkommen können.

Der erste Abschnitt von Gaudium et Spes endet mit folgenden Worten:

Ist doch ihre eigene Gemeinschaft (scil. die Kirche, RP) aus Menschen gebildet, die, in Christus geeint, vom Heiligen Geist auf ihrer Pilgerschaft zum Reich des Vaters geleitet werden und eine Heilsbotschaft empfangen haben, die allen auszurichten ist. Darum erfährt diese Gemeinschaft sich mit der Menschheit und ihrer Geschichte wirklich engstens verbunden. ${ }^{6}$

Die Bedeutung der Stimmungen steht demnach in engstem Zusammenhang mit der konkreten menschlichen Geschichte, in der die Kirche sich selbst als Akteurin versteht. Sie sind wirkmächtige historische Triebkräfte. Diese Geschichte wird als eschatologisches Unterwegs-Sein, als „Pilgerschaft“, als Bewegung und Prozess verstanden. Was die Gläubigen dabei mit allen anderen Menschen verbindet, sind jene Grundstimmungen, die alle Menschen teilen können. Darin erkennt die Kirche einen wesentlichen Beitrag des christlichen Glaubens.

\subsection{Zur Fragestellung}

Im folgenden Beitrag gehe ich der Frage nach, worin im Kontext von Flucht und Migration der Beitrag einer Theologie bestehen könnte, die den Stimmungen Freude und Hoffnung, Trauer und Angst theologische Relevanz einräumt. Von welcher Angst, von welcher Trauer kann in diesem geschichtlichen Kontext die Rede sein? Und worin gründen Freude und Hoffnung, die der christliche Glaube in dieser herausfordernden Situation einbringen könnte?

Flucht und Migration sind aus einer bibeltheologischen Perspektive loci theologici, d.h. theologiegenerierende Orte - Orte, an denen Theologien entstanden sind, die sich im Leben von Menschen bewährt haben. Zentrale Texte des

5 Vgl. das scholastische Prinzip gratia supponit naturam.

6 Siehe Internetquellen: Pastorale Konstitution Gaudium et Spes. 
Alten Testaments sind im Kontext von Flucht und Migration entstanden: Exil und Vertreibung, Aufbruch ins Unbekannte und Diaspora, Erfahrungen von Fremdheit und Not. Dabei sind „Theologien der Migration“ entstanden. ${ }^{7}$ Auch zahlreiche Texte des Neuen Testaments greifen in ihrer Deutung der Ereignisse mit Jesus von Nazareth und in der Reflexion eigener Erfahrungen von Fremdheit und Diaspora auf diese theologischen Motive zurück. Nicht zuletzt diese fundamentaltheologische Bedeutung von Flucht und Migration hat das kirchliche Lehramt dazu bewogen, auch die globalen Migrationen der Gegenwart als „Zeichen der Zeit“" zu bezeichnen, ,als eine Herausforderung, die es beim Aufbau einer erneuerten Menschheit und in der Verkündigung des Evangeliums des Friedens zu entdecken und zu schätzen gilt ${ }^{* 8}$.

Inmitten der Konflikte rund um die globale Jahrhundert-Herausforderung entsteht demnach eine erneuerte Menschheit und lässt sich das Evangelium auf neue Weise entdecken und verkünden. Diese herausfordernde theologische Sichtweise versuche ich im Folgenden unter der Perspektive der eingangs erwähnten Fragestellungen zu reflektieren.

\subsection{Was sind Freude und Hoffnung, Trauer und Angst?}

Vorweg wäre allerdings noch zu klären, was ich unter den hier benannten Stimmungen verstehe, wenn es sich dabei um geistige Beziehungsformen zur Wirklichkeit handeln soll, die Gefühle wohl umfassen, aber diese transzendieren.

Trauer beschreibt den Prozess geistiger Neuorientierung angesichts des Schmerzes, der einen Menschen auf allen Ebenen des Daseins erfasst, wenn er bzw. sie eine für ihn bzw. sie existentiell bedeutsame und lebenswichtige Wirklichkeit - einen Menschen, eine Lebensform, eine Weltsicht uvm. - verliert oder verloren hat. ${ }^{9}$ Es geht dabei nicht allein um die materielle Abwesenheit dieser Wirklichkeit, sondern Denken, Fühlen und Handeln sind dermaßen von diesem Schmerz erfüllt, dass im Erleben die ganze Welt verloren gegangen und keine Zukunft mehr vorstellbar scheint. In diesem Prozess besteht die Aufgabe des Geistes darin, eine Art neuer innerer ,geistiger Landkarte“ zu entwickeln, indem der Verlust schrittweise anerkannt wird und so wieder Zukunft in den Blick kommen und Leben möglich werden kann. Da insbesondere in modernen Kulturen Zeit, Rituale und soziale Beziehungen für die Begleitung eines solchen Prozesses nicht selten für viele Menschen fehlen ${ }^{10}$ und der Schmerz zudem mit-

7 Dazu habe ich vielfach publiziert, u. a. Polak / Jäggle 2012, S. 570-598; Polak 2015b, S. 47-78; Polak 2013, S. 195-214; Polak 2014a, S. 87-114; Polak 2014b, S. 233-296; u. a.

8 Siehe Internetquellen: Päpstliche Kommission. Die Instruktion begründet sich bibeltheologisch.

9 Wegweisend dazu immer noch das Werk von Elisabeth Kübler-Ross.

10 Vgl. Pock / Feeser-Lichtenfeld 2011. 
unter unerträglich scheint, wird Trauer als Prozess geistiger Neuorientierung oft unterdrückt. „Deckgefühle“ ersetzen die Trauer: z. B. Gleichgültigkeit, Depression, Resignation oder Hass. Durchlebte Trauer allerdings eröffnet Hoffnung auf Zukunft. Sie ist die Bedingung der Möglichkeit für Hoffnung. Ohne Trauer gibt es keine substantielle Hoffnung, sondern höchstens ,positives Denken“ oder Optimismus, der - wie der Pessimismus - eine geistige „Verstimmung “11 ist, da er Schmerz und Leid ausblenden muss, um sich gut zu fühlen.

Hoffnung ist die geistige Neuorientierung in der Welt, die dabei unterstützt, schwierige, schmerz- und leidvolle, sogar „böse“ Lebenssituationen wahrzunehmen, anzuerkennen und in ihnen Sinn- sowie Zukunftsperspektiven zu erkennen und zu entwickeln. Mit Schönfärberei oder Verharmlosung von Schmerz und Leid angesichts von Verlusterfahrungen hat dies gerade nichts zu tun, im Gegenteil. Hoffnung setzt die Annahme von Trauer im Angesicht von Schmerz und Leid geradezu voraus. Insofern es sich dabei um eine geistige Beziehungsform zur Wirklichkeit handelt, meint Hoffnung aber keinesfalls das innere Gefühl, dass „schon irgendwie alles wieder gut wird“. Hoffnung gewährt keine Garantie auf ein „happy end“. Hoffnung verweigert jedoch die Anerkennung von Leid, Schmerz und des Bösen als letztgültige Wirklichkeiten. Insofern ist Hoffnung untrennbar verbunden mit Widerstand und praktischem Handeln. Auf diese Weise gibt Hoffnung dem Übel in der Vielfalt seiner Erscheinungsformen nicht Recht, sondern widersteht ihm durch das Entwickeln von Denk- und Handlungsalternativen, die das Leben fördern sollen. Von daher gilt Hoffnung in der christlichen Spiritualität auch als Tugend, als eingeübte Einstellung sowie Verhalten angesichts des Bösen, von Leid und Tod. Ermöglicht wird dies aus theologischer Sicht durch die Orientierung an Gott und das Aufrechterhalten der Beziehung zu ihm auch in schwierigen Zeiten. Insbesondere in den prophetischen Gestalten der Heiligen Schrift wird erkennbar, wie sich Hoffnung konkret zeigt: Schonungslos werden Leid und Böses beim Namen genannt - und zugleich Denkund Handlungsalternativen benannt und getan, die die Situation verändern können.

Angst beschreibt jene geistige Verfassung, in der das Leben als solches bedroht zu sein scheint und auf dem Spiel steht. Solche Angst kann eine angemessene wie unangemessene Reaktion auf die Welt sein, in der sich ein Mensch vorfindet. Entscheidend ist dabei das Erleben, von der Beziehung zu anderen Menschen, zur Welt und zu Gott abgeschnitten und getrennt zu sein. Angst vereinzelt und isoliert Menschen voneinander und lässt die Welt bedrohlich und eng erscheinen. Sie mindert Leben und zerstört menschliche Beziehungen. Als zunächst notwendige Reaktion des menschlichen Organismus auf das Erleben von Gefahr ist sie

11 So hat dies mein Lehrer, Professor Karl-Augustinus Wucherer-Huldenfeld, em. Ordinarius für Christliche Philosophie an der Katholisch-Theologischen Fakultät der Universität Wien, bezeichnet. 
ethisch zwar neutral, aber zugleich eine „narzisstische“12 Wirklichkeitswahrnehmung, d.h. sie ist besorgt um das eigene Überleben und verliert die Anderen aus dem Blick. Insofern menschliche Angst zudem kulturell induziert ist, d.h. durch Bedeutungszuschreibungen erzeugt werden kann, ist sie sozial doppelt gefährlich. Politisch induzierte Angst kann zu Ausgrenzungen, Vertreibung und Krieg gegen andere Menschen führen - und hat dies in der Geschichte auch immer wieder getan. Angst bedarf also der ethischen Sozialisation durch das Erlernen des Denkens an andere Menschen und der Förderung von emotionaler und geistiger Empathie. Um die existentielle Bedeutung von Angst weiß offenbar auch die Heilige Schrift, wenn sie mit ihr in der Genesis die Entfremdung Adams von Gott beginnen lässt $($ Gen 3,10) und sich die Aufforderung „Fürchtet Euch nicht!" $366 \mathrm{mal}^{13}$ in der Heiligen Schrift finden lässt. Offensichtlich ist Angst die zentrale Quelle allen menschlichen Übels. ${ }^{14}$ Zugleich zeigt die Fähigkeit, Angst zu haben, aber auch die menschliche Erkenntnis und Anerkennung der eigenen Endlichkeit, theologisch gesagt: der Gebundenheit an eine größere, göttliche Wirklichkeit. Angst anerkennt die menschliche Fragilität und ist ein Ausdruck der Lebendigkeit. Ein Mensch, der keine Angst kennt, ist zu fürchten, weil er seine Begrenzung vergessen hat. Gegenmittel gegen diese tiefe, existentielle Angst, die untrennbar zum Leben gehört, sind Begegnung, Beziehung und die Erfahrung des Eingebettet-Seins in diese. Der christliche Glaube bietet also nicht religiöse Weltanschauungen als Opium gegen die Angst an, sondern Beziehung als „Heimat" in einer endlichen und gefährdeten Existenz.

Demgegenüber beschreibt Freude die Erfahrung der innigen Verbundenheit des Menschen mit sich selbst, mit anderen, der Welt und Gott. Sie ist der Inbegriff von Lebendigkeit: der Erfahrung, dass die Menschen untereinander und mit Gott in Liebe verbunden sind; das Eingebettet-sein in den „Strom des Lebens“. Insofern hat Freude nicht notwendig mit lautem Lachen oder gar „Spaß“ zu tun, sondern beschreibt die spirituelle Erfahrung der inneren Einheit der Menschheit untereinander und mit Gott. Nicht ohne Grund ist sie daher in nahezu allen spirituellen „Schulen“ der christlichen Tradition sowie in der Liturgie von elementarer Bedeutung - insbesondere bei Ignatius von Loyola.

Inwiefern sind nun bzw. können diese vier Grundstimmungen, denen das Konzil eine so hohe Bedeutung zuschreibt, im Kontext von Flucht und Migration bedeutsam sein oder werden?

12 Vgl. zur Analyse der Angst: Nussbaum 2014a, S. 55 ff.

13 So Zulehner 2016, S. 145.

14 Dies ist z. B. die Grundthese von Drewermann 1977. 


\section{Politik der Angst}

\subsection{Angst als gesellschaftliche Grundstimmung}

Welche eminent politische Rolle Angst im Kontext der „neuen religiösen Intoleranz" in den Migrationsgesellschaften Europas spielt, hat die US-amerikanische Philosophin Martha Nussbaum gezeigt und zu einer sozialethischen Theorie weiterentwickelt, wie man Gefühle im Kontext von Politik zivilisieren kann. ${ }^{15}$ Dabei zeigt sie nicht nur an unzähligen Beispielen, wie maßgeblich politische Entscheidungen von Emotionen, insbesondere Angst, beeinflusst werden, sondern auch - aus theologischer Sicht interessant -, dass Liebe als "Gegengift“ zu Angst in politischen Kontexten hoch relevant ist. Emotionen bestimmen die Politik und bedürfen daher der ethischen Bildung.

Auch der Politologe Dominique Moïsi ${ }^{16}$ widmet sich der Analyse der Bedeutung von Emotionen in globalpolitischen Zusammenhängen und beschreibt die Länder des Westens als Regionen der Angst. Nach jahrhundertelanger Welthegemonie fürchten sie einerseits die Wirtschaftskraft jener ,aufholenden Länder“, die nun ihrerseits ihren Anteil vom ökonomischen „Kuchen“ einfordern: Brasilien, Russland, Indien, China, Mexiko und Südafrika. Andererseits fürchten sie das „Ressentiment“ jener Länder, die sich durch den europäischen (Wirtschafts-)Kolonialismus und den US-amerikanischen Imperialismus gedemütigt fühlen und Widerstand zu leisten beginnen: die muslimischen Länder von Marokko bis Pakistan, aber auch Teile Asiens und Lateinamerikas. Europa hat demnach Angst, ökonomisch überholt bzw. beherrscht zu werden sowie durch Gewaltausbrüche, Terrorakte und Vergeltungsakte im Bereich der Versorgung mit fossilen Brennstoffen zerstört zu werden.

Heinz Bude wiederum wirft einen soziologischen Blick auf die interne Befindlichkeit der westlichen Wohlfahrtsgesellschaften und konstatiert „Angstwelten" einer Gesellschaft, deren Mitglieder den sozialen Ausschluss und Abstieg ebenso fürchten wie das Bedroht-sein durch Mehr- und Minderheiten und eine allgegenwärtige Sinnlosigkeit trotz überwältigender Lebensmöglichkeiten. ${ }^{17}$

All diesen Analysen ist gemeinsam, dass sie zeigen, dass Angst als gesellschaftliche Grundstimmung ein keinesfalls neues und schon gar nicht unbegründetes Gefühl ist. Denn tatsächlich sind die europäischen Gesellschaften schon seit langem mit globalen Herausforderungen und Auswirkungen auf Europa konfrontiert, die sie bisher in Quantität und Qualität so recht und schlecht ausblenden konnten - ebenso wie den Anteil an Verantwortung für diese Entwicklungen.

15 Vgl. Nussbaum 2014b.

16 Vgl. Moïsi 2009.

17 Vgl. Bude 2014. 
Mit der Ankunft von schutzsuchenden Menschen in einem bisher noch nicht da gewesenem Ausmaß brechen diese tief sitzenden Emotionen seit dem Herbst 2015 an die gesellschaftliche Oberfläche. Menge und Herkunft der Flüchtlinge konfrontieren Europa mit allen Weltproblemen auf einen Schlag. Europa kann nicht mehr wegschauen. Obwohl keinesfalls unvorhersehbar ${ }^{18}$ und zu einem nicht unwesentlichen Teil selbst erzeugt ${ }^{19}$, findet sich Europa in einer Situation wieder, der insbesondere die politisch Verantwortlichen der Nationalstaaten nicht gewachsen sind - oder gewachsen sein wollen, müssen sie um die internationalen Entwicklungen doch schon seit langem Bescheid wissen. „Es ist geradezu verwerflich, Migration erst dann zu problematisieren, wenn sie über den eigenen Gartenzaun schwappt “20, könnte man mit dem Schriftsteller Ilija Trojanow urteilen.

Dabei ist Europa schon seit dem 20. Jahrhundert Einwanderungskontinent und zur Migrationsgesellschaft transformiert. ${ }^{21}$ Migration ist deshalb freilich noch keinesfalls als europäische „Normalität“ anerkannt. Ein problem- und nicht chancenorientierter Diskurs dominiert ungebrochen den öffentlichen und politischen Raum und wird seit der wachsenden Ankunft von Flüchtlingen politisch

18 Seit Jahrzehnten künden Migrationsexperten die Ankunft von Migranten aus den armutsgezeichneten Regionen der Welt an. Vgl. dazu den überaus instruktiven Sammelband von Cohen 1995, der bereits vor 20 Jahren das historische und globale Ausmaß der internationalen Migrationen bewusst gemacht hat. Jedem denkenden Menschen muss auch klar gewesen sein, dass die Kriege in Syrien, im Mittleren Osten und in Afrika zu Fluchtbewegungen führen würden. Kardinal Francesco Montenegro von Agrigent/ Lampedusa erzählte bei der Deutschen Bischofskonferenz am 17. Februar 2016 von warnenden Stimmen bereits in den 50er-Jahren. Auch das Sterben von tausenden Menschen entlang der europäischen Grenzen im Mittelmeer ist nicht erst seit dem Besuch 2013 von Papst Franziskus auf Lampedusa bekannt, sondern wird von zivilgesellschaftlichen Organisationen schon seit den 90er-Jahren thematisiert. So dokumentiert z.B. die Menschenrechtsorganisation „Borderline-Europe“ seit Jahren das Sterben an Europas Grenzen, um Schweigen darüber zu brechen: Siehe Internetquellen: Borderline-Europe.

19 In diesem Zusammenhang sei an den europäischen Kolonialismus, den europäischen Waffenhandel, die Duldung und Unterstützung von Diktatoren in Regionen, von deren Erdöl Europa abhängig ist sowie an die europäischen Wirtschaftsinteressen in den Regionen der Herkunftsländer der Flüchtlinge erinnert. Ein Beispiel für die nähere Zukunft: Die „New Alliance for Food Security and Nutrition“ - ein Bündnis führender Industriestaaten mit multinationalen Konzernen wie Cargill, Dupont, Danone, Monsanto, Nestle, Unilever usw. - wird durch den damit verbundenen Strukturwandel der dortigen Landwirtschaft - industrielle Massenbewirtschaftung unter der Kontrolle internationaler Konzerne - Millionen Kleinbauern ihrer Existenzgrundlage berauben. Wohin sollen sie gehen, um zu überleben? Vgl. Trojanow 2016, S. 12.

20 Ebd., S. 11.

21 Vgl. Livi Bacci 2015. 
angefacht. Dabei werden Migration und Flucht, zwei verschiedene Phänomene, die auch differenzierter politischer Lösungen bedürfen, vermischt und mutieren zum Inbegriff der Bedrohung Europas. In zahlreichen europäischen Staaten instrumentalisieren die politisch Verantwortlichen die aufkommende Angst für politische Eigeninteressen.

Dabei können sie auf die in der Bevölkerung vorfindbaren Gefühle zurückgreifen. ${ }^{22}$ Für Österreich hat der Pastoraltheologe Paul M. Zulehner dazu eine Studie vorgelegt, in der er den emotionalen Reaktionen der Bevölkerung auf die Ankunft der Flüchtlinge nachgeht. Er identifiziert dabei Ärger, Sorge und $\mathrm{Zu}$ versicht. In seinen Interpretationen der Gefühle, die Angst vor „Islamisierung“ ebenso umfassen wie Angst vor dem Verlust von Wohlstand und christlicher Identität, kommt er zu dem Schluss, dass die europäischen Angstgesellschaften vor der zentralen Aufgabe der „Ent-Ängstigung“ stehen, die diffuse Ängste in rationale Besorgnis verwandelt und so jene Liebe und Solidarität freisetzen kann, die es zum Entwurf nachhaltiger und zukunftsorientierter Politik benötigt.

\subsection{Menschenfeindlichkeit als politische Antwort?}

Ausmaß von und Reaktionen auf Angst werden maßgeblich von politischen Diskursen gesteuert, die den konkreten Ereignissen einen heuristischen Rahmen und damit verbunden Handlungsoptionen offerieren. So konnten die Politikwissenschaftler Sieglinde Rosenberger und Gilg Seeber zeigen, dass das Ausmaß fremdenfeindlicher Einstellungen nicht mit der Anzahl von Migranten in einem Staat, sondern mit dem Vordringen des rechtspopulistischen Diskurses in die Mitte der Gesellschaft zusammenhängt, ${ }^{23}$ der die Ängste der Menschen instrumentalisiert und solcherart vermehrt.

Der umgekehrte Zusammenhang gilt übrigens ebenfalls: Wo es politischen Gemeinden (konkret: im Bundesland Oberösterreich) gelungen ist, gemeinsam mit Bevölkerung und NGO's ein Konzept zur Flüchtlingsaufnahme zu entwickeln und dabei auf die entsprechenden Konflikte einzugehen, sank die Zustimmung zu rechtspopulistischen Einstellungen signifikant. ${ }^{24}$ Konkrete Begegnung und Beziehung mit Flüchtlingen, die ein Gesicht, einen Namen und eine Lebensgeschichte bekommen, sind das beste „Gegengift“ gegen Ängste aller Art.

Derzeit lässt sich freilich quer durch die Länder Europas das Erstarken konservativer, rechtspopulistischer und sogar neofaschistischer Einstellungen und Parteien beobachten, die die begründeten Ängste der Menschen vor realen Bedrohungen und Veränderungen als „Angst vor den Flüchtlingen“ deuten und so in das politische Konzept des Rassismus einordnen. Indem man pseudo-ethisch

22 Vgl. Zulehner 2016.

23 Vgl. Rosenberger / Seeber 2011, S. 165-190.

24 Vgl. Rosenberger/Seeber 2016. 
daran appelliert, „,die Ängste der Menschen ernst nehmen zu müssen“, werden sie politisch benützt und verstärkt. Insbesondere die sog. Visegrád-Staaten Osteuropas greifen dabei auf nationalistische und neofaschistische Praktiken zurück. Vermutlich liegt dies daran, dass in diesen Staaten nach Jahrzehnten des politischen Totalitarismus mit dessen Konzept homogener Einheitsgesellschaften noch $\mathrm{zu}$ wenig Zeit und Interesse vorhanden ist, die eigene belastete Vergangenheit zu reflektieren, die auch in den Einstellungen der Menschen Spuren hinterlassen hat. Die Anomie osteuropäischer Gesellschaften nach dem Zerfall des realen Kommunismus äußert sich auch im Verfall moralischer Substanz und mangelndem Demokratie- und Menschenrechtsbewusstsein. ${ }^{25}$ Menschenrechtsverletzungen und rassistische Praktiken des Ausschlusses von Menschengruppen sind in gewissem Sinn historisch vertraute „Lösungen“ politischer Probleme. Dass dies auch für große Teile der Bevölkerungen Westeuropa zutrifft, das seit Ende des Zweiten Weltkrieges in demokratischen, rechtsstaatlichen Verhältnissen lebt und ausreichend Zeit zur Geschichtsreflexion hatte, war freilich in diesem Ausmaß unabsehbar. Denn auch im Westen grassieren Menschenhass, neofaschistische Einstellungen und Rassismus.

Rassismus meint in meinem Verständnis nicht bereits die besorgte oder ängstliche Reaktion auf Erfahrungen von Fremdheit in der Begegnung mit (vermeintlich oder tatsächlich) fremden kulturellen oder religiösen Verhaltensweisen. Ethisch und politisch entscheidend sind die Praxiskonsequenzen, die daraus gezogen werden. Fremdenfeindlichkeit ist als solche auch keinesfalls „natürlich“, sondern eine kulturell erlernte emotionale Reaktion. Grundlage dafür ist der Rassismus als jene ordnungspolitische Theorie und Praxis, die gesellschaftliche Konflikte dadurch „löst“, dass Wert und Würde eines Menschen von dessen Zugehörigkeit zu einer sozialen Gruppe abhängen. ${ }^{26}$ Diese Gruppen gelten ideologisch als ungleichwertig und werden innerhalb des Gemeinwesens hierarchisch gereiht. Einem „Wir“ stehen „die Anderen“ gegenüber, eine Wahrnehmungsweise, die sich auch bei wohlmeinenden und sozial engagierten Bürgern finden lässt. So tief ist dieses Deutungsmuster in der Kultur verankert. Dem Rassismus gelten die minderwertigeren Gruppen sodann als verantwortlich für die aktuellen Schwierigkeiten. Heute sind das nicht mehr biologisch, sondern ökonomisch minderwertige Menschen: also jene, die keinen ökonomischen Nutzen bringen oder die Gesellschaft ökonomisch belasten. Rassismus operiert auf der Basis des bekannten „Sündenbockmechanismus“"27, der Konflikte in einer Gruppe dadurch „,befriedet“, dass eine Person oder eine ganze Gruppe für das Wohl der Gemeinschaft geopfert wird.

Rassismus leugnet die Einheit des Menschengeschlechtes. Historisch diente er, vor allem seit dem 19. Jahrhundert, immer wieder als strategisch höchst effizi-

\footnotetext{
25 Vgl. Tomka / Szilárdi 2016.

26 Vgl. Geulen 2014.

27 Vgl. dazu das Werk von René Girard.
} 
enter Ablenkungsmechanismus in Situationen sozialer Spannungen, die durch unrechte und ungerechte Machtkonzentrationen in Politik und Ökonomie sowie Armut verursacht waren. Statt die tatsächlichen politischen und ökonomischen Ursachen zu suchen und Lösungen zu finden, lenkt der Rassismus hervorragend von unangenehmen Fragen wie ungleicher Verteilung von Macht und Ressourcen $\mathrm{ab}$ und dient der Vermeidung der Selbstkritik aller Beteiligten. Als politische „Strategie“ führte er im 19. und 20. Jahrhundert zur Unterdrückung, Vernichtung und sodann systematischen Ermordung von Menschengruppen, allen voran der Juden. Trotzdem diese katastrophischen Abstiegserfahrungen nach dem Zweiten Weltkrieg zu einer wesentlichen Quelle der Entwicklung von Menschenrechten, Demokratie und der sogenannten europäischen Werte wurden, liegen rassistische Deutungs- und Handlungsmuster nach wie vor im kollektiven Gedächtnis bereit. Werden die Zeiten rauer, lassen sie sich offenkundig von - geschichtsvergessenen und verantwortungslosen - Politikern jederzeit wieder abrufen und benützen.

Wie weit rassistische Einstellungen verbreitet sind und in die Mitte der Gesellschaft vorgedrungen sind, zeigt eine Reihe empirischer Studien. Die LangzeitStudie „Deutsche Zustände“28 (2002-2011) des Instituts für interdisziplinäre Konflikt- und Gewaltforschung der Universität Bielefeld erforschte über zehn Jahre hinweg das Syndrom „gruppenbezogener Menschenfeindlichkeit ${ }^{“ 29}$. Dessen ideologischer Kern besteht in der Auffassung von der Ungleichwertigkeit von Menschen. Nachgewiesen wurde dabei der enge Zusammenhang zwischen sozialen und ökonomisch prekären Lebens- und Gesellschaftsverhältnissen, damit verbundenen - realen wie imaginierten - Deprivationserfahrungen und dem Anstieg menschenfeindlicher Einstellungen. Die kulturelle Vielfalt einer Gesellschaft wird demnach erst in einem Kontext als Bedrohung wahrgenommen, in dem das subjektive Erleben zunimmt, dass die Gesellschaft ihren Zusammenhalt verliert. Wer der Ansicht ist, in der Gesellschaft seinen gerechten Anteil nicht zu bekommen, soziale Spaltungen wahrnimmt, für die Zukunft keine Orientierung hat, sich sozial nicht unterstützt und politisch machtlos fühlt, macht dafür die kulturelle Vielfalt verantwortlich. Im Hintergrund stehen die Vorstellungen einer homogenen Gesellschaft, die durch kulturell Andere bedroht wird, sowie ökonomistische Einstellungen gegenüber schwachen Gruppen, die als nicht nützlich für die Gesellschaft gelten und keine verwertbare Leistung erbringen. Das Ausmaß dieser „rohen Bürgerlichkeit“, wie die Studienautoren dieses Einstellungsmuster nennen, war schon im Untersuchungszeitraum, vor der Ankunft der Flüchtlinge, konstant hoch und korrelierte signifikant mit sozioökonomischen Krisen und dem Erleben einer zunehmend „entsicherten“ Gesellschaft.

\footnotetext{
28 Heitmeyer 2002-2012.

29 Dazu werden gezählt: Fremdenfeindlichkeit, Rassismus, Islamfeindlichkeit, Antisemitismus, Abwertung von Behinderten, Obdachlosen, Roma und Sinti, Asylwerbern, Langzeitarbeitslosen, Sexismus, Homophobie und das Eintreten für Etabliertenvorrechte.
} 
Auch Studien zu Antisemitismus und Islamophobie zeigen eine seit einigen Jahren kontinuierliche Zunahme an Diskriminierungen und tätlichen Übergriffen. Europaweite Forschungen der Europäischen Grundrechteagentur FRA ${ }^{30}$ oder der „European Islamophobia Report 2015“31 , aber auch nationale Erhebungen wie der jüngste österreichische Antisemitismusbericht $2015^{32}$ verdeutlichen, dass der Hass gegen Juden und Muslime wächst. Hemmschwellen sinken und Gewaltbereitschaft steigt. In Bezug auf den Antisemitismus ist das auf das Ansteigen islamistischer Übergriffe zurückzuführen. Viele Muslimas wiederum bekommen in Beschimpfungen, Verspottungen und Bespuckt-werden den antimuslimischen Hass zu spüren, der im Kontext der Flüchtlingsdebatten politisch und medial geschürt wird. Beide Gruppen sind auch Opfer der grassierenden verbalen Gewalt in den sozialen Medien, die einen wesentlichen Beitrag zur Verschärfung des sozialen Klimas leisten.

Zeitgleich zeigen Studien zu rechtsextremen Einstellungen in der Gesellschaft ein komplexes Bild. So weisen die „Mitte-Studien“33 der Universität Leipzig zwar im Zeitraum von 2002-2014 einen insgesamt sinkenden Rechtsextremismus sowie abnehmende Ausländerfeindlichkeit für Deutschland nach. Allerdings lassen sich rechtsextreme und antidemokratische Einstellungen quer durch die Wähler aller Parteien in der Gesellschaft finden. Demnach ist der politisch sichtbare Rechtsextremismus die Manifestation des Ausmaßes rechtsextremer Einstellungen in der ganzen Gesellschaft. Beunruhigend mit Blick auf die aktuellen politischen Entwicklungen im Zuge der Flüchtlingskrise ist dies insofern, als die jüngste Erhebung von 2014 gezeigt hat, dass vor allem bestimmte Migrantengruppen: Asylwerber, Sinti und Roma sowie Muslime, in einem extremen Ausmaß abgewertet werden. 2014 lehnten „84,7 \% der Befragten in den neuen und 73,5 \% der Befragten in den alten Bundesländern die Forderung ab, der Staat solle großzügig bei der Prüfung von Asylanträgen vorgehen. Wirkliche Verfolgung erlitten zu haben oder von ihr bedroht zu sein, gestanden nicht einmal $50 \%$ der Deutschen in Ost wie West den Asylsuchenden zu. “34 Auch das Ausmaß autoritärer und gewaltbereiter Aggression ist - vor allem bei jungen Erwachsenen und Männern - konstant hoch bzw. im Steigen. Desgleichen gibt es eine hohe Anzahl von Unentschiedenen (bis zu einem Drittel der Befragten) gegenüber rechtsextremen Einstellungen. Alles in allem dokumentiert die Studie ein großes antidemokratisches Risikopotential, das im Zuge der jüngeren Ereignisse rund um die Flüchtlinge aktiviert werden kann - und seit Herbst 2015 auch wird. Die Studienautoren deuten diese durchaus widersprüchlichen Entwicklungen als nach wie vor weit verbreitete Empfänglichkeit für die Ideologie der Ungleich-

\footnotetext{
30 Vgl. Internetquellen: Europäische Agentur für Grundrechte (FRA).

31 Vgl. Internetquellen: Bayrakli / Hafez 2015.

32 Vgl. Internetquellen: Forum gegen Antisemitismus.

33 Decker / Kiess / Brähler 2014.

34 Ebd., S. 63.
} 
wertigkeit von Menschen. Ihnen zufolge handelt es sich um einen „sekundären Autoritarismus": Im Kontext der hegemonialen Macht ökonomistischer Ideologien ermöglicht die Identifikation mit diesen dem Einzelnen Teilhabe an der Gesellschaft. Um des (realen oder erhofften) Wohlstands willen sind Menschen bereit, sich dieser Logik zu unterwerfen, durchaus auch um den Preis der Beschädigung des eigenen und des Lebens der Kinder, um in dieser Dynamik von Leistung, Konkurrenz und Erfolg mitzuhalten. Das Ressentiment gegen bestimmte Gruppen, die diese Teilhabe bedrohen, verweist auf eine autoritäre Dynamik, den „sekundären Autoritarismus“. Zu dieser Dynamik gehört, dass sich die dabei entstehenden Aggressionen aber eben nicht gegen die Autorität - die autoritäre Logik ökonomischer Strukturen - selbst richten, sondern gegen Schwächere: Asylsuchende, Roma und Sinti und Muslime.

Wie eng rechtspopulistische und -extreme Einstellungen mit Angst im Kontext sozioökonomischer Krisensituationen zusammenhängt, hat 2011 bereits der britische Wirtschaftswissenschafter Guy Standing ${ }^{35}$ gezeigt, der aufgrund der fortschreitenden Prekarisierung der Arbeitswelten infolgedessen vor der Entstehung eines „politischen Monsters“ warnt. Denn Prekarisierung erzeugt Angst, die ab einem bestimmten Ausmaß in irrationale Hysterie abgleitet. Die aktuellen Erfolge faschistoider Rechtsparteien in ganz Europa oder auch von Donald Trump in Amerika zeigen, dass die „,vierte Industrialisierung“, die nach Standing traditionelle Gesellschaftsstrukturen völlig auflöst, längst ein bedrohliches Ausmaß an Armutsproduktion oder Angst vor Armut und sozialem Ausschluss erzeugt zu haben scheint. Die wachsende „Armee“ von Arbeitslosen (vor allem jungen Menschen) oder in prekären Arbeitsverhältnissen kämpfenden Menschen bleibt politisch nicht folgenlos. Migranten und Flüchtlinge können in dieser Atmosphäre rasch als Konkurrenten wahrgenommen bzw. politisch und ökonomisch dazu gemacht werden.

Die Schwierigkeiten, die kulturelle Differenz und Erfahrungen von Fremdheit mit sich bringen, sollen mit diesem Befund nun weder schön geredet noch verharmlost werden. Aber die entscheidende Gefährdung des sozialen und Weltfriedens geht nicht von Diversität aus, sondern von Ungleichheit und Ungerechtigkeit bei der Verteilung von Besitz, Ressourcen und Macht. Selbstverständlich hat Europa das Recht und die Pflicht, all jene Gesetze und Werte zu schützen und zu verteidigen, auf die sich z. B. die Europäische Union gründet:

[...] die Achtung der Menschenwürde, Freiheit, Demokratie, Gleichheit, Rechtsstaatlichkeit und die Wahrung der Menschenrechte einschließlich der Rechte der Personen, die Minderheiten angehören. Diese Werte sind allen Mitgliedsstaaten in einer Gesell-

35 Standing 2011. Ähnlich für Deutschland auch der Wirtschaftswissenschaftler Fratscher 2016. 
schaft gemeinsam, die sich durch Pluralismus, Nichtdiskriminierung, Toleranz, Gerechtigkeit, Solidarität und die Gleichheit von Frauen und Männern auszeichnet. ${ }^{36}$

Gerade jetzt wäre die Stunde der praktischen Bewährung dieser Werte.

Ohne Zweifel werden zu dieser Werte-Frage noch intensive Debatten geführt werden müssen ganz unabhängig von Fragen nach Flucht und Migration. Aber die Unterstellung, dass die europäischen Werte durch „die“ Flüchtlinge und Migranten bedroht seien, ist nicht nur ideologisch und rassistisch; sie blendet die Bedrohung der europäischen Werte im Inneren Europas durch Rassismus, Rechtsextremismus und Autoritarismus aus und projiziert sie auf die „Anderen“. Zahlreiche Studien und historische Belege weisen nach, dass Zusammenleben in Verschiedenheit zwar keine einfache Angelegenheit und in jeder Generation neu zu lernen ist, aber durchaus möglich war und ist. Dies gilt auch für das Zusammenleben mit Muslimen, die als die ,kulturell Fremden“ definiert werden. ${ }^{37}$ Bedroht und zerstört wurde und wird dieses Zusammenleben aber immer wieder durch die politische Instrumentalisierung kultureller Differenz zur Spaltung von Gesellschaften und Durchsetzung hegemonialer Interessen. Die Aufgabe der Zivilisierung kultureller Werte, die in jeder Kultur humane wie inhumane Anteile haben, betrifft Einheimische wie Zugewanderte und Flüchtlinge gleichermaßen: zu erkennen, dass Menschen verschiedene Lebensweisen (Kulturen) haben, die alle der ethischen Zivilisierung bedürfen; denn keine Kultur ist ein ethischer Wert „an sich“. Weiters ist von allen anzuerkennen, dass jeder einzelne Mensch und alle Menschen das gemeinsame Menschsein teilen und „Menschen sind wie wir“ sowie gemeinsam ein Ethos und eine Politik zu entwickeln, die der Gleichheit und Verschiedenheit der Menschen gerecht werden. Dabei werden Einstellungen und Verhaltensweisen aller Beteiligten zivilisiert - und nicht Individuen und Kollektive. Entwickelt wird dabei das, was die Tradition „Gemeinsinn“ nennt. ${ }^{38}$

\footnotetext{
36 Siehe Internetquellen: Vertrag über die Gründung der Europäischen Union.

37 Erinnert sei an das religiös und kulturell vielfältige Spanien des 8.-15. Jahrhunderts oder an Bosnien-Herzegowina, insbes. Sarajewo, das ,Jerusalem Europas“. Europa selbst ist aus dem dreifachen Glauben - jüdisch, christlich, muslimisch - an den einen Gott hervorgegangen, vgl. Bergolte 2006.

38 Überlegungen zu diesem komplexen Zusammenhang von kultureller Verschiedenheit und universalem Ethos, Barbarei und Zivilisation im Kontext von Migration bietet Todorov 2010 .
} 


\subsection{Die Fülle und Gleichzeitigkeit der Bedrohungen}

Das Bedrohliche an den aktuellen politischen Entwicklungen sind die „Shifting Baselines“ der öffentlichen, medialen und politischen Diskurse. Damit bezeichnet der Sozialpsychologe Harald Welzer ${ }^{39}$ die oft erstaunlich schnelle und unbemerkt bzw. verleugnete Veränderung normativ-ethischer Referenzrahmen der Wahrnehmung und Deutung von Ereignissen und Situationen. In der Auseinandersetzung mit Tätern des Nationalsozialismus konnte er jene sozialpsychologischen Mechanismen aufzeigen, die dazu führen, dass Menschen sich immer noch für moralisch integer halten, obwohl sie bereits längst inhumanen ethischen Vorstellungen zustimmen - und zwar durch ihr ganz konkretes, alltägliches Verhalten, das keinen Widerspruch erhebt, sondern durch Schweigen, Beobachten und Mitmachen zustimmt. Normenverschiebungen finden zuerst immer praktisch statt und schaffen sodann Gelegenheitsstrukturen unethischen Verhaltens, das sodann im Nachhinein ethisch legitimiert wird.

Die aktuelle Situation kann einen also durchaus an vergangene Zeiten erinnern. Die „Lösung“ internationaler politischer, ökonomischer sowie sozialer Probleme mittels menschenfeindlich-rassistischer Politik stellt für Europa ,vertrautes Gefilde“ dar. Sozioökonomische und politische Transformationskrisen wurden historisch betrachtet bereits mehrfach von Rassismus als ordnungspolitischem Deutungs- und Handlungsmustern begleitet. ${ }^{40}$ Elitär von den Bevölkerungen abgekoppelte und den gesellschaftlichen Entwicklungen gegenüber ahnungs- und hilflose Führungseliten beantworteten die soziale Frage des 19. Jahrhunderts mit einem nationalistisch argumentierten Ersten Weltkrieg. Die davor aufblühende Globalisierung, die rasanten Innovationen in Wissenschaft und Politik, Technik und Kunst sowie die kulturelle Internationalisierung wurden so abrupt gestoppt. ${ }^{41}$ Die Faschismen und Totalitarismen des 20. Jahrhunderts waren die Reaktion auf die Weltwirtschaftskrisen und Armutsproblematik der 30er-Jahre, denen die politischen und gesellschaftlichen Eliten ignorant, widerwillig, ohnmächtig und erschöpft gegenüberstanden. ${ }^{42}$ Wie eng verbunden diese „Lösungen“ wirtschaftlicher Krisen mit dem Ausschluss von Menschengruppen verbunden ist, zeigt die Ermordung der Juden als absolutem zivilisatorischem Tiefpunkt Europas. Jedes Mal standen letztendlich nicht die Fragen nach den wahren Ursachen von Armut und Elend, nach unrechten und ungerechten politischen und ökonomischen Ordnungsverhältnissen im Zentrum, sondern „,siegten" Kampf und Krieg um Vormachtstellung auf Kosten ganzer Bevölkerungsgruppen, allem voran der Juden.

39 Vgl. Welzer 2007.

40 Über diese Zusammenhänge anhand der 1930-er Jahre: vgl. Polanyi ${ }^{2} 1990$.

41 Vgl. Blom 2009.

42 Vgl. Blom 2014. 
Ist es abwegig, in den aktuellen Ereignissen strukturelle Ähnlichkeiten zu erkennen? Wiederholen sich politisch riskante Prozesse, die Europa im 20. Jahrhundert in den Abgrund geführt haben, nunmehr auf globalem Level?

Immerhin: Kaum diskutiert wird aktuell über Fluchtursachen oder die Verweigerung, diese entschlossen zu bekämpfen. Beschwiegen wird z. B. die fossile Wirtschaft und die Abhängigkeit Europas von Regimen im Nahen Osten oder der europäische Wirtschaftsimperialismus, der den westlichen Lebensstil und dessen Konsumismus erst ermöglicht. Weder das Versagen zahlreicher Staaten der EU noch deren grassierender Mangel an Solidarität sind Thema einer breiten Öffentlichkeit; auch nicht die kaputtgesparten Sozialsysteme und die innereuropäische Armut, geschweige denn die Macht ökonomischer Oligarchen oder die politische Phantasielosigkeit und moralische Dekadenz zahlreicher Parteipolitiker. Über etwaige historische Zusammenhänge - welche Rolle z. B. Europa bei der Genese und Aufrechterhaltung der Terrororganisationen IS und Boko Haram spielt - wird erst recht nicht gerne nachgedacht. Regelmäßige Finanz-Skandale, die die Sezession der Reichen von der Verantwortung für das Gemeinwohl dokumentieren - Stichwort Panama-Papers - oder Debatten um globale ökonomische Macht- und Besitzverhältnisse finden bei weitem nicht jene langanhaltende Aufmerksamkeit und Tatbereitschaft, die der Sicherung der Europa-AuBengrenzen und der Abwehr von Flüchtlingen gewidmet wird. Ebenso wenig reflektiert man die steigende Zahl brennender Flüchtlingsheime oder stellt die Frage, was gegen rechtsextreme Gruppierungen unternommen werden könnte.

Stattdessen wird ein Begriff wie „Gut-Mensch“ zu einem salonfähigen Schimpfwort; wer sich für eine „Willkommenskultur“ einsetzt, wird als „naiv“ und ,verantwortungslos“ diffamiert; wer ökonomische oder politische Machtfragen stellt, wird als ,links“ oder „Altkommunist“ bezeichnet. Statt Fluchtursachen mithilfe internationaler Friedens- und Entwicklungspolitik offensiv zu bekämpfen oder gar „Marshall-Pläne“ zum Wiederaufbau der Kriegsregionen anzudenken, werden politische Energie und materielle Ressourcen in Zäune und Massenflüchtlingslager außerhalb Europas sowie Abschiebungsprogramme investiert. Die damit verbundene Desensibilisierung politischer Sprache, die die Beugung z.B. von Menschenrechten zur Sicherung von Eigeninteressen legitimiert und Gewalt gegen Flüchtlinge verschleiert, sind alarmierende Elemente einer verstörenden Dynamik. So spricht man von „zivilmilitärischen Aktionen“ an den Grenzen, depersonalisiert schutzsuchende Familien in eine anonyme Flüchtlingsmasse oder erklärt die „Festung Europa“ - bis vor kurzem ein negativ konnotierter Begriff - zum politischen Programm. Gesprochen wird über „Wirtschaftsflüchtlinge“, wobei vergessen wird, wie viele Millionen Europäer in den vergangenen beiden Jahrhunderten unterwegs waren, um die eigene Lebenssituation ökonomisch zu verbessern. ${ }^{43}$ Armut, Unrecht und Ungerechtigkeit bekommen erneut auf der Ebene der politisch Verantwortlichen nicht den Stel- 
lenwert, der ihnen aufgrund ihrer historischen Bedeutung bei der Entstehung sozialer Konflikte und Kriege zustehen müsste.

Geschichte wiederholt sich nicht, zumindest nicht ident. Freilich, Karl Marx hat einst darauf aufmerksam gemacht ${ }^{44}$ dass sie sich zweimal ereignet: einmal als Tragödie, das zweite Mal als Farce:

Die Menschen machen ihre eigene Geschichte, aber sie machen sie nicht aus freien Stücken, nicht unter selbstgewählten, sondern unter unmittelbar vorgefundenen, gegebenen und überlieferten Umständen. Die Tradition aller toten Geschlechter lastet wie ein Alp auf dem Gehirne der Lebenden. Und wenn sie eben damit beschäftigt scheinen, sich und die Dinge umzuwälzen, noch nicht Dagewesenes zu schaffen, gerade in solchen Epochen revolutionärer Krise beschwören sie ängstlich die Geister der Vergangenheit zu ihrem Dienste herauf, entlehnen ihnen Namen, Schlachtparole, Kostüm, um in dieser altehrwürdigen Verkleidung und mit dieser erborgten Sprache die neuen Weltgeschichtsszene aufzuführen. ${ }^{45}$

Marx verweist auf Zusammenhänge, die aus der Sicht der zeitgenössischen psychoanalytischen Sozialpsychologie durchaus plausibel erscheinen. Er beschreibt jene historischen Prozesse, in denen über Generationen hinweg die jeweils nachfolgende Generation - konfrontiert mit neuartigen politischen Herausforderungen - auf die Verhaltensmuster der Vorfahren zurückgreift und deren „Rollen“ übernahm, um nicht nur die anstehenden Probleme zu lösen, sondern auch die der Vorfahren zum Ende zu bringen. ${ }^{46}$

So übersetzt der Anfänger, der eine neue Sprache erlernt hat, sie immer zurück in seine Muttersprache, aber den Geist der neuen Sprache hat er sich nur angeeignet, und frei in ihr zu produzieren vermag er nur, sobald er sich ohne Rückerinnerung in ihr bewegt und die ihm angestammte Sprache in ihr vergisst. ${ }^{47}$

Für neue Probleme benötigt man neue Perspektiven und Lösungen. Stattdessen wird die Gegenwart in die Vergangenheit zurückübersetzt.

In der psychoanalytischen Sozialpsychologie nennt man diesen Prozess den transgenerationalen Transfer von Traumata. Diese können sich auch auf politische Ereignisse beziehen, wie das auch jüngere Studien zur Erklärung des Wiedererstarkens z.B. rechtsextremer Einstellungen bei jungen Menschen in Deutschland beschreiben. Demzufolge kann die nicht geleistete Trauerarbeit der Kriegsgeneration - angesichts der Niederlage im Krieg; der nicht reflektierten Schuldgeschichte, auch als „Mitläufer“; der unaufgelösten affektiven Beziehung zum „Führer“ Adolf Hitler, von dem man sich belogen und getäuscht fühlte; oder

44 Vgl. Marx / Engels 1972, S. 115-123.

45 Ebd.

46 Z. B. Brunner / Lohl / Pohl / Winter 2011.

47 Ebd. 
schlicht Leid, Armut und Verluste an Lebenszeit oder Menschen - dazu führen, dass dieser hoch ambiguöse Gefühls,,knoten“ eine emotionale „Krypta“"48 bildet. Die darin verdrängten Gefühle sind zwar unsichtbar, werden aber als emotionale Grundstimmung an die Nachfahren weitergegeben. Diese wiederum werden aus Liebe und Treue zu ihren Eltern, die stärker sind als jede schulische Bildung, ${ }^{49}$ diese ungelösten Emotionen zu einem Abschluss zu bringen versuchen. Dafür werden entsprechende Settings und Szenarien unbewusst „gesucht“ und inszeniert. Freuds „Wiederholungszwang“ kann sich demnach auch politisch ereignen, wenn die entsprechenden Rahmenbedingungen dafür gegeben sind. Das Angstund Bedrohungsszenario, das rund um die Ankunft der Flüchtlinge geschaffen wird, erscheint so in einem anderen Licht. Schließlich stünden rational betrachtet auch andere Wahrnehmungen und politische Reaktionen zur Verfügung.

Erklärbar würde so z. B. die befremdliche Ansprechbarkeit v. a. junger Männer auf antidemokratische, rechtspopulistische oder rechtsextreme Einstellungen. ${ }^{50}$ Junge Menschen sind europaweit von sozialem Ausschluss und Armut sowie Orientierungslosigkeit in Bezug auf die Zukunft in besonderer Weise bedroht. Sie sind die Verlierer der aktuellen Finanz- und Wirtschaftskrisen. ${ }^{51}$ Dies ist eine sozial tickende Zeitbombe. Denn bei entsprechendem politischen Diskurs sind vor allem junge Menschen anfällig für rassistische Deutungen. Auch der - im Vergleich zu dieser Affinität weitaus geringere - Zustrom junger europäischer Muslime zum IS wird so nachvollziehbarer. Es sind vor allem jene jungen, in einer Alltagsreligiosität gerade nicht verankerten säkularen Muslime, in deren Augen alle politischen Utopien gescheitert sind, die Gesellschaft besser und gerechter zu gestalten. ${ }^{52}$ Solcherart ernüchtert erhoffen sie in der Religion „Erlösung“, spiegeln aber genau besehen den westlichen Gesellschaften deren eigenen Nihilismus ebenso wieder $^{53}$ wie die strukturelle Rücksichtslosigkeit gegenüber jungen Menschen, auf deren Kosten jahrzehntelang gelebt wurde. Im Unterschied zur Nachkriegsgeneration, deren Lebenssituation nur besser werden konnte, wissen junge Menschen in Europa heute, dass sie das Wohlstandsniveau nur, falls überhaupt, unter unglaublichem Druck halten werden können oder überhaupt von sozialem Abstieg bedroht sind. An den extremen Rändern - im Rechtsextremismus und jugendlichen Dschihadismus - wird das Generationenproblem erkennbar.

\footnotetext{
48 Brunner 2011, S. 169-194.

49 Vgl. Welzer / Moller / Tschuggnall 2002.

$50 \quad$ Vgl. Decker u.a. 2014, S. 61.

51 Vgl. Internetquellen: Bertelsman-Stiftung; 26 Millionen Kinder und junge Menschen sind in der EU von Armut und sozialer Ausgrenzung bedroht; die Arbeitslosenraten betragen in den Mitgliedsstaaten bis zu $50 \%$.

52 Vgl. Khosrokhavar 1997.

53 Vgl. Manemann 2015.
} 
In diesem Ambiente bieten sich schutzsuchende Menschen hervorragend als jene Projektionsfläche an, auf die aktuell sämtliche Probleme und die damit verbundenen Emotionen bezogen werden können.

Der Kontext ist freilich heute ein anderer als vor dem ersten oder zweiten Weltkrieg. Neu sind das globale Ausmaß und die Gleichzeitigkeit der Krisen. Dies beginnt bei der Quantität und Qualität internationaler Migrationen infolge moderner Mobilitäts- und Kommunikationsmöglichkeiten, die transnationale Migration zur Normalität werden lassen. Die globale Bedrohung zeigt sich weiters in den Auswirkungen des Klimawandels, der wiederum vor allem die Ärmsten trifft und zu Millionen „Katastrophenflüchtlingen“ führen wird. Nicht zuletzt verbreitet der internationale Terror weltweit Angst und spaltet Gesellschaften. Denn indem der totalitäre Terror im Kontext des Islamhasses gedeutet wird, der seinerseits in Europa auf jahrhundertelange Narrative der islamischen Bedrohung zurückgreifen kann, werden auch europäische Muslime stigmatisiert und isoliert. Sie drohen aus der „Grauen Zone“ der Mehrfachzugehörigkeiten (,islamisch, demokratisch, europäisch") in den Machtbereich der Extremisten getrieben zu werden. Hinzu kommt das global fragile aktuelle Finanzsystem, das mit seinen entkoppelten Finanzmärkten und politisch unkontrollierten, international agierenden multinationalen Konzernen „räuberische Formationen“ entwickelt hat, die strukturell zur Exklusion ganzer Menschengruppen führen, die ökonomisch überflüssig werden.$^{54}$ Das Zugleich all dieser bedrohlichen Entwicklungen macht die Weltlage nun gerade nicht beruhigender - zumal mit Blick auf die militärische Ausrüstung und das Waffenarsenal in der Welt sowie rasende mächtige (alte) Männer und deren AtlatInnen, die um ihre Vorherrschaft in der sich neu ordnenden Welt fürchten.

\subsection{Angst: Begründet und existenziell}

Mit historischer Rationalität betrachtet gibt es also mehr als ausreichend Gründe, Angst zu haben. In der Tat steht die Welt vor immensen Herausforderungen, Gefahren, Risken und tödlichen Bedrohungen. Man muss keine Apokalyptikerin sein, um dies nüchtern wahrzunehmen. Das weit verbreitete Grundgefühl von Angst hat gute und berechtigte Ursachen.

Die Fokussierung dieser begründeten Ängste auf die Flüchtlinge ist allerdings aus dieser Perspektive alles andere als rational; höchstens aus einer psychoanalytischen Perspektive als Abwehrmechanismus der anstehenden Selbsterkenntnis und Aufgaben ist es verstehbar. Sozialpsychologische und historische Befunde zeigen, dass es sich dabei um Verschiebung und Verdichtung von Angst handelt. Die mit Angst oft verbundene Aggression richtet sich sodann folgerichtig nicht gegen die wirklichen Ursachen und deren als übermächtig erlebte Verantwortli-

54 Dazu: Sassen 2015. 
che, sondern gegen eine schwächere Gruppe. Diese Verschiebung wiederum kann von den politischen und ökonomisch mächtigen Verantwortlichen genützt werden, um von der eigenen Verantwortung abzulenken. Flüchtlinge gehören zu den verletzbarsten und ohnmächtigsten Menschen: Sie sind vollkommen abhängig davon, ob sie aufgenommen werden und Unterstützung finden. Sie sind die „idealen“ Opfer. Damit sollen sie keinesfalls idealisiert werden, denn selbstverständlich gibt es auch unter ihnen Kriminelle, Gewalttäter und Terroristen.

Zugleich sind die Flüchtlinge Überbringer schlechter Nachrichten für Europa. Erst sie „Zwingen“ seit dem Herbst 2015 die europäischen Bevölkerungen zum Wahrnehmen der global multifaktoriell bedrohlichen Lage. Sie sind „Botschafter" ${ }^{\text {"55 }}$, denn sie machen die Fülle und Drastik der Bedrohungen sichtbar: Ausschluss und Armut, Gewalt und Krieg, Klimakatastrophen und Terror. Sie sind das „Fenster“56 zu einer Welt, deren Notlagen Europa bisher wahrzunehmen verweigert hat. Sie sind auch die „Spiegel ${ }^{157}$ Europas, weil sie - wenn man über die Ursachen ihrer Ankunft nachdenkt - die europäische Mitverantwortung - und Schuld - in Geschichte und Gegenwart in Erinnerung rufen.

Deshalb werden Flüchtlinge wohl auch von vielen so gehasst. Denn seit jeher wird der Botschafter schlechter Nachrichten für deren Inhalt verantwortlich gemacht. Zudem werden nur die wenigsten gerne mit der eigenen Wahrheit konfrontiert. Schließlich ist es einfacher, gegen die Ohnmächtigen, Armen und Schwachen zu kämpfen als gegen die Ursachen von Ohnmacht, Armut und Schwäche.

Die berechtigte Furcht vor globalen Bedrohungen und deren lokalen Auswirkungen verdichtet sich also in der Angst vor Flüchtlingen.

Lassen sich dahinter aber nicht noch elementarere, existentielle Ängste finden, die sich auch durch politische Lösungen nicht ändern lassen werden? Existenzielle Ängste, die in den Bereich der Spiritualität fallen? Ängste, die mit dem Mensch-Sein an sich zusammenhängen, die der sich selbst erschaffende, autonome Mensch des fortschrittsgläubigen Westens ignorieren zu können glaubte?

Flüchtlinge spiegeln nämlich auch wieder, wovor alle Menschen Angst haben: Verlust, Ohnmacht, Schwäche, Leid, Armut, Bedürftigkeit und Abhängigkeit. Flüchtlinge erinnern an die Endlichkeit des Menschen, seine Begrenztheit und an den Tod. Nicht zuletzt rufen sie auch in Erinnerung, wovor sich eine Mehrheit der Menschen in Europa offenbar unglaublich ängstigt: Die Angst vor Veränderung. Denn angesichts des Ausmaßes der Herausforderungen ist eines gewiss: Nichts wird so bleiben, wie es war. Dabei ist es gleichgültig, ob Europa die Flüchtlinge aufnimmt und integriert und so ein weltpolitisches „Vorbild“ für die gesamte Welt werden könnte - oder sich abschottet, was das Ressentiment und den Hass gegen

\footnotetext{
55 Winkler 2015.

56 Flusser 1992, S. 30.

57 Ebd.
} 
den Westen in die nächste Generation transferieren wird. Die Welt ist im Umbruch, so oder so.

An dieser Stelle ist es überfällig, über die Angst der Flüchtlinge zu sprechen, die faktisch weder in politischen, medialen noch auch wissenschaftlichen Debatten eine Rolle spielt, so sehr sind die Einheimischen mit sich selbst beschäftigt. Deren Lebenssituation steht auch in diesem Beitrag nicht im Zentrum, wenngleich sie eigene Forschung verdient. Aber auch Flüchtlinge haben Angst: um ihr Leben und das ihrer Kinder, angesichts einer vollkommen ungesicherten Zukunft, ohne Heimat und oft mit nichts als ein paar Habseligkeiten, die sie mitgenommen haben - schlichtweg oft vor dem nächsten Tag. Auch sie sind konfrontiert mit Erfahrungen von Fremdheit und irritiert von kultureller Differenz. Sie erleben existentielle Bedrohung, Zerbrechlichkeit des Lebens, Abhängigkeit vom guten Willen und der Macht anderer hautnah. Relativiert das nicht das Getön der Angst-Politik in Europa? Warum überdecken Gewalttaten einiger Flüchtlinge die Realität jener großen Mehrheit an Menschen, deren Angst vor dem Leben in der Heimat so groß geworden sein muss, dass sie die Angst vor dem Aufbruch ins Ungewisse auf sich nahmen, unter ihnen unzählige Kinder und junge Menschen?

\subsection{Trauer?}

Möglicherweise ist diese existentielle Grundstimmung der Angst vor Endlichkeit und Veränderung eine der Ursachen, warum von Trauer in Europa so wenig wahrzunehmen ist. Dabei wäre angesichts des Verlusts von Lebensweisen und Illusionen Trauer notwendig, um wieder neue Hoffnung für die Zukunft entwickeln zu können. Die Erfahrungen, dass Europa vieles wird verändern müssen von der internationalen und Wirtschaftspolitik bis hin zum Lebensstil der einzelnen Bürger - bedingen einen schmerzhaften Abschied vom Europa der vergangenen Jahrzehnte. Europa wird sich mit der Ankunft der Flüchtlinge sozial und kulturell verändern. Der Abschied ist überfällig, denn wir erleben nicht nur einen epochalen Wandel, sondern einen Wandel der Epoche. ${ }^{58}$ Eine neue Zeit hat längst begonnen, die Welt und mit ihr Europa sind längst in einem Übergang. Fakt ist, dass weder die internationalen Migrationen und deren Ursachen in absehbarer Zeit zu Ende sein werden. Die Kriegs- und Armuts-Krisenherde in Afrika werden ebenso erhalten bleiben wie der Nahe und Mittlere Osten ein Pulverfass darstellt. 60 Millionen Menschen, die 2015 weltweit vor Krieg und Hunger auf der Flucht waren, werden nicht über Nacht verschwinden. ${ }^{59}$ Europa ist mit einer langen Zukunft konfrontiert, in der es als reicher Kontinent aufgefordert ist, für die Lösung all dieser Probleme Mitverantwortung zu übernehmen und zugleich sich selbst zu verändern. Jetzt könnte sich Europa bewähren und seine Geschichte

58 Vgl. Internetquellen: Mcelwee, Joshua J. 2015.

59 Holtkamp 2016, S. 9. 
fruchtbar machen, der es die berühmten europäischen Werte mühsam abgerungen hat und deren Praxisrelevanz unter Beweis stellen. Wer, wenn nicht dieser Kontinent?

Dazu muss sich Europa freilich grundlegend verändern. Dieser Abschied bedingt Trauer. Ebendiese Trauer könnte für Europa einen Schritt in jene Freiheit bedeuten, die es benötigt, um Lösungen zu finden. Eine Freiheit, die überdies vielleicht sogar neue Lebensqualitäten mit sich bringen könnte. Denn auch der Kampf um das Aufrechterhalten des Status quo des Lebens in Europa bedeutet für wachsende Menschengruppen nicht nur Dauerbedrohung durch Abstiegsangst, sondern auch eine Zunahme an Depressionen und Burnout, erhöhte Fragilität von Beziehungen und soziale Einsamkeit. Der gefürchtete Verlust könnte vielleicht auch einen Gewinn an Lebensqualität - Freude und Hoffnung - mit sich bringen.

\section{Zeichen der Freude und Hoffnung}

Verlässt man die makropolitische bzw. -ökonomische Vogelperspektive und richtet den Blick auf die gesellschaftliche Mesoebene, auf der Menschen verschiedener sozialer, kultureller und religiöser Herkunft in den Migrationsgesellschaften Europas schon längst ihr Leben teilen, einander unterstützen und vonund miteinander lernen und feiern, stößt man keinesfalls ausschließlich auf Angst oder Trauer. Große Teile der Zivilgesellschaft und zahlreiche NGO's haben sich offenkundig schon länger auf die sich verändernden Zeiten eingestellt und engagieren sich nicht nur für Flüchtlinge, sondern schon seit Jahren für gesellschaftlichen Wandel, für gerechte Politik und ein gutes Zusammenleben in Verschiedenheit. Niemand wird die Szenen an den Bahnhöfen München oder Wien vergessen, als wochenlang Menschen aus allen sozialen Schichten und unterschiedlichen Weltanschauungs- bzw. Religionsgemeinschaften Flüchtlinge willkommen hießen. Ebenso war der zivilgesellschaftliche Widerstand in Österreich und Deutschland gegen die Linie der Regierungspolitik ein politisches Novum. Die Zahl jener Menschen, die sich für Rechtsstaatlichkeit, Demokratie und Menschenrechte sowie Anerkennung kultureller Pluralität einsetzen, ist nicht so klein, wie Medien und Parteien den Anschein erwecken. Auch dies gehört zu einem gegenüber den Vorzeichen des ersten wie zweiten Weltkrieges veränderten Kontext.

Leider gibt es in diesem Feld des zivilgesellschaftlichen Engagements nur wenige repräsentative Studien, denen man Quantität und Qualität der damit verbundenen Einstellungen und Praxiserfahrungen entnehmen und diese für die breite Bevölkerung fruchtbar machen könnte. In wessen Interesse ist dieses Phänomen? Qualitative Case-Studies über „Good-Practice“-Modelle sind und wären jedenfalls überaus hilfreich in der aktuellen Situation. 
Mittlerweile scheint die Gruppe jener Menschen kleiner zu werden, die sich hier zu Beginn voller Elan engagiert haben. Erschöpfung und Resignation angesichts der Dauer und vor allem der mangelnden strukturellen Unterstützung durch die politischen Verantwortungsträger haben im Verein mit der Verweigerung der Solidarität zahlreicher Nationalstaaten und einem problem- und fluchtfixierten Mediendiskurs dazu geführt, dass sich auch engagierte Menschen mit ihren Ängsten und Sorgen im Stich gelassen fühlen.

Dennoch lässt sich insgesamt feststellen, dass dort, wo sich Menschen und Gemeinschaften auf die Veränderungen einlassen, die die Ankunft der Flüchtlinge mit sich bringt, nicht nur die Hoffnung wächst, dass die Probleme lösbar sind, sondern auch neue Freude entsteht. An dieser Stelle müsste ich nun die Vielzahl jener konkreten Erzählungen niederschreiben, die mir ehrenamtliche Engagierte über ihre Erfahrungen im Zusammenleben mit Flüchtlingen berichten. Es sieht aus, als würden Flüchtlinge nicht nur Angst und Hass, sondern auch das Beste in den Menschen wecken können. ${ }^{60}$

Die Fülle dieser konkreten Einzelerfahrungen gibt Hoffnung, dass dort, wo Menschen sich nicht von der kollektiven Angst lähmen oder aufhetzen lassen, sondern konkret an ihrem Ort das tun, was ihnen möglich ist, Dynamiken der Hoffnung und Freude freigesetzt werden. Insbesondere aus dem Bereich der Kirchen, die sich in Österreich und Deutschland als maßgebliche Akteure in der Aufnahme und politischen Unterstützung von Flüchtlingen engagieren, scheint deren Ankunft eine Art Initialzündung zu neuer Vitalität zu sein. Da bauen überalterte Frauenorden ihre Klöster um und entdecken ihr Ordenscharisma neu; da arbeiten in Wien plötzlich Pfarren zusammen, die die Kooperation jahrelang verweigert haben; da kommen Menschen in die Gemeinden, die seit Jahren keinen Fuß in eine Gemeinde gesetzt haben. Aber auch NGO's berichten von solchen Prozessen: Neue Allianzen entstehen, unzählige Freiwillige melden sich zur Mitarbeit, Studierende engagieren autonom Flüchtlingsprojekte mit Sprachkursen und Gemeinschaftsabenden. In Österreich zeigt z.B. die „Landkarte der Hilfsbereitschaft “61 eine überbordende Fülle an Initiativen und Menschen, die voller Freude von ihren Erfahrungen berichteten. Was Migrationsforscher ebenfalls seit Jahren beschreiben - dass Migration Gesellschaften ökonomisch, sozial, kulturell, religiös bereichern kann und seit Jahrhunderten demographisch gesehen eine Erfolgsgeschichte darstellt ${ }^{62}$ - wird durch tausende

\section{Konkrete Erzählungen z. B. in Naprushkina 2015.}

61 Ö1, einer der wenigen öffentlich-rechtlichen Sender, die sich kritisch und lösungsorientiert mit dem Flüchtlingsthema auseinandersetzen, hat im Herbst 2015 ein Projekt gestartet, indem in zahlreichen Beiträgen und auf einer Online-Plattform konkrete „Geschichten vom Helfen“ berichtet wurden, die von der Solidarität von Personen, Vereinen und Gemeinden berichteten und Erfahrungen vermittelten: Vgl. Internetquellen: „Geschichten vom Helfen: Landkarte einer neuen Zivilgesellschaft“.

62 Vgl. Livi Bacci 2011. 
Fallbeispiele im Alltag belegt. Warum finden diese Erfahrungen so wenig Eingang in den öffentlichen und politischen Diskurs? Weil man mit der kritischen Autonomie von Bürgern keine Wahlen zu gewinnen glaubt? Weil man der destruktiven Energie rechtspopulistischer Parteien mehr Durchsetzungsvermögen zutraut? Weil Freude im Unterschied zu Angst und Hass stiller, bescheidener, unsichtbarer ist? Weil der Blick auf das konkrete, einzelne Ereignis, auf konkrete einzelne Menschen und deren Geschichte schwieriger, langwieriger ist und mehr Zeit benötigt - und vielleicht auch langweiliger ist als das gebannte Starren auf Konzentrationen politisch-militärisch-ökonomischer Machtblöcke und Dynamiken des Bösen? Weil die journalistische Darstellung und Analyse des „Guten“ banaler erscheint und weniger lustvoll und quotenträchtig ist als die „des Bösen“? Weil Angst intensiver ist als Freude und Hoffnung?

Welche Kräfte werden sich durchsetzen? Aus historischer Sicht gibt es wenig Grund zu Freude und Hoffnung. Denn in solchen Krisen- und Transformationszeiten, wie sie die Welt derzeit auf globaler Ebene erlebt, wurde zumeist der Angst der Vorrang gegeben und haben sich die autoritären Kräfte der Reaktion, der Gewalt und des Krieges durchgesetzt. Zugleich lehrt die Geschichte aber auch, dass es langfristig vor allem die zunächst unsichtbaren Kräfte der Solidarität, Gerechtigkeit und Liebe waren, die die neuen, humanisierenden Ideen und Praktiken in die Welt gebracht haben; freilich begleitet von Millionen Opfern.

Darf die langfristige Geschichte der Zivilisierung und die Freude, die gelebte Humanität in die Welt bringt, ausreichend Grund zur Hoffnung geben, dass die Menschheit diesmal zeitgerecht innehält, der Angst nicht das letzte Wort überlässt und auf sich historisch desavouiert habende „Lösungen“ wie Rassismus, Exklusion, Vertreibung und Krieg zurückgreift? Darf man hoffen, dass sich diesmal die entscheidenden Kräfte in Wirtschaft, Wissenschaft, Politik zusammentun und für die Neuartigkeit der Herausforderungen auch neue Lösungen suchen, die dem Überleben und Leben der Menschheit dienen? Oder ist eine solche Hoffnung naiv?

Flüchtlinge könnten jedenfalls aus einer solchen Sichtweise Botschafter einer „,neuen Welt" sein, die nicht mehr von partikularistischen Stammes- und RudelMentalitäten - nationaler, ethnischer, religiöser oder politischer Art - oder dem Kampf um Hegemonie dominiert wird, sondern in der die Menschheit begreift, dass sie eine ist und zusammenhelfen muss und kann. Indem Flüchtlinge das Gefährdungspotential der Gegenwart ins Bewusstsein rufen, wären sie so auch Spiegel und Fenster einer zukünftigen, menschlicheren Welt, die mit zu gestalten jetzt maßgeblich auch in der Verantwortung Europas liegt. 


\section{Kann Theologie etwas beitragen?}

\subsection{Emotional-Geistige Unterstützung der Menschheitsgeschichte}

Mit einem solch universal-menschheitlichen Ansatz bin ich freilich bereits in der Theologie gelandet. Nicht, dass allein die katholische Theologie so denkt. Diese Ausrichtung hat sie erst - nach langem Widerstand gegen Religionsfreiheit, Demokratie und Menschenrechte - mit dem Zweiten Vatikanum wieder gewonnen und damit an das biblische Erbe angeschlossen. Aber ebendieser theologische Ausgangspunkt - die Einheit der Menschen mit Gott und untereinander und der Glaube an den einen Gott, der in und mit einer Menschheit lebt und wirkt - bildet das Herzstück des theologischen Beitrags in Zeiten von Flucht und Migration. Flüchtlinge und Migranten sind nicht „die Fremden“ oder „die Anderen“. Sie können Erfahrungen von Fremdheit auslösen, aber sie sind Menschen und als solche Teil der einen Menschheit. Diese Einheit zu repräsentieren und zu fördern - zu verstehen nicht als Uniformität sondern als Prozess des Eins-Werdens bildet laut Lumen Gentium 1 das Zentrum des katholischen Selbstverständnisses und das Ziel der Heils-Geschichte Gottes mit den Menschen. Wenn Gaudium et Spes diese Sichtweise im Kontext der konkreten Wirklichkeit praktisch durchbuchstabiert und dabei Freude und Hoffnung, Trauer und Angst an den Beginn dieses Prozesses stellt, haben die Kirchenväter offenbar einen höchst aktuellen neuralgischen Punkt getroffen. Sie erkennen und anerkennen die wirkmächtige Kraft von Stimmungen als affektiv-geistig-leiblichen Triebkräften der Geschichte. Dabei geben sie den scheinbar „schwächeren“ Stimmungen, die in der Politik selten gefördert werden, aber Vorrang. Der Dominanz der Angst und der Notwendigkeit der Trauer werden Freude und Hoffnung vorangestellt. Im Teilen dieser Grundstimmungen benennt das Konzil den ersten und vielleicht wichtigsten Beitrag der Kirche und ihrer Gläubigen zum Weltgeschehen.

Wie relevant eine solche emotional-geistige „Unterfütterung“ für politisch„wohlgeordnete“ Gesellschaften ist, hat Martha Nussbaum in ihrer Studie zu „Politischen Emotionen“63 belegt. ,Wohlgeordnet“ sind in ihrer Sicht Gesellschaften dann, wenn marginalisierte Gruppen auf der Basis der Anerkennung der Gleichwertigkeit aller und jedes einzelnen Menschen in Bezug auf Würde und Rechte inkludiert sind, d.h. die Probleme von Stigmatisierung, Exklusion und Marginalisierung gelöst sind und sozial gerechte Umverteilung gelingt. ${ }^{64} \mathrm{Um}$ Gesellschaften zu motivieren, Dynamiken in Richtung dieses idealen Ziels zu fördern, bedarf es der Unterstützung durch „Emotionen“, die auch für Nussbaum geistige Realitäten, d.h. nicht nur Affekte sind, sondern immer schon Einschätzungen und Bewertungen beinhalten. ${ }^{65}$ In diesem Sinn sind Emotionen nicht nur

63 Nussbaum 2014b, S. 13.

64 Vgl. ebd., S. 23.

65 Vgl. ebd., S. 18. 
gefährlich, sondern sogar notwendig, um gerechte Gesellschaften aufbauen zu helfen, da sie abstrakten politischen Werten und Normen die notwendige Tiefe und Nachhaltigkeit verleihen. Liebe und Mitgefühl spielen in dem „Programm“, das Nussbaum zur Förderung einer verantwortungsbewussten Politik der Gefühle für liberale Gesellschaften entwickelt, eine entscheidende Rolle. Da allerdings alle Emotionen zunächst ,eudämonisch“"66 sind, d. h. die Welt vom Standpunkt des Individuums aus bewerten und sich auf den engeren Umkreis von Familie, Freunde und Bekannten beschränken, bedarf es geistiger Vorgänge, um den „Betroffenheitsradius “67 von Menschen zu weiten auf jene, die als zunächst nichtzugehörige Fremde wahrgenommen werden. Nussbaum räumt dabei der Rolle von Kunst, Poesie und Literatur, aber auch Humor und Spiel und durchaus auch der Religion eine Schlüsselrolle ein, da sie das menschliche Fühlen, Wahrnehmen und Denken bilden und weiten können.

An diese Analyse kann nun der Beitrag der Theologie im Kontext von Flucht und Migration gut anschließen.

\subsection{Praktischer Beitrag}

Dass „emotional-geistige Beziehungsformen“ durchaus relevante praktische soziale und politische - Folgen haben können, lässt sich am Einsatz der Kirche im Kontext von Flucht und Migration erkennen. Seit Jahrzehnten sind die christlichen Kirchen in Europa wichtige Akteure in diesem Feld, insbesondere auf internationaler Ebene.

Die Katholische Kirche hat sich als eine der ersten internationalen Institutionen mit Migrationspolitik auseinandergesetzt. Bereits 1970 gründete Papst Paul VI. eine „Päpstliche Kommission“68 zu dieser Thematik, die 1988 durch Papst Johannes Paul II. in den „Päpstlichen Rat der Seelsorge für Migranten und Menschen unterwegs“69 umgewandelt wurde. Die Apostolische Konstitution „Exsul Familia“ (1952), die Instruktion „De pastorali migratorum cura: Nemo est“ (1969) und - wegweisend in ihrem internationalen Horizont für die Gegenwart - die Instruktion „Erga migrantes caritas Christi“ (2004) - entwickeln die dieses Engagement tragenden liegenden theologischen Grundlagen. Im Angesicht von Millionen Migranten - „displaced persons“ - nach dem Zweiten Weltkrieg wurde 1951 die Internationale Katholische Kommission für Migration (IMC) gegründet, die bis heute die Arbeit katholischer Organisationen für Migranten, Flüchtlinge und Heimatlose koordiniert und sich national und interna-

\footnotetext{
66 Ebd., S. 25.

67 Ebd., S. 26.

68 Zur Geschichte siehe Internetquellen: Päpstliche Kommission.

69 Vgl. Internetqelle: Päpstliche Kommission.
} 
tional auf politischer Ebene für deren Interessen einsetzt. ${ }^{70}$ Seit 1991 - eröffnet von Johannes Paul II. - gibt es seine alljährliche „Botschaft“ zum Welttag der Migranten und Flüchtlinge. ${ }^{71}$ Der Vatikan ist ein global aktiver politischer Akteur in Migrationsangelegenheiten: ${ }^{72} \mathrm{Er}$ war beteiligt an der Erarbeitung der Internationalen Konvention der UN zum Schutz der Rechte migrantischer Arbeiter und ihrer Familien und unterstützt seit langem die Entwicklung internationalen Rechts zum Schutz von Migranten und Flüchtlingen. ${ }^{73}$ In jüngster Zeit sind auf nationaler Ebene vor allem die „Leitsätze des kirchlichen Engagements für Flüchtlinge" der Deutschen Bischofskonferenz vom Februar 2016 herauszustreichen. ${ }^{74}$ Die Priorität, die Papst Franziskus dieser Thematik einräumt, steht also in jahrzehntelanger kirchlicher Tradition. ${ }^{75}$

Auch die anderen christlichen Kirchen sind international in der Flüchtlingsund Migrationspolitik höchst aktiv. Die „Churches' Commission for migrants in Europe" ist eine ökumenische Organisation, die die Vision einer inklusiven Gesellschaft durch „advocacy“ für Migranten, Flüchtlinge und Minderheiten auf nationaler Ebene propagiert, sich für Einheit in Verschiedenheit einsetzt und die Unterscheidung in Fremde und „Eingeborene“ beseitigen möchte. ${ }^{76}$ Derzeit besteht sie aus 28 Mitgliedskirchen aus 18 verschiedenen europäischen Staaten ${ }^{77}$ und kooperiert mit zwei weiteren Organisationen: Der „Conference of the European Churches" (CEC) und dem „World Council of Churches“ (WCC). Informelle Zusammenarbeit gibt es auch mit der Katholischen Kirche. Flüchtlingsschutz, Arbeitsmigration, Bekämpfung von Menschenhandel, internationale Entwicklungspolitik und Förderung inklusiver Gemeinschaften gehören zum Programm ebenso wie die Entwicklung konkreter Handlungsvorschläge und Richtlinien wie z. B. die Einrichtung sicherer Zugangspassagen zu Europa. 2010 wurde in diesem Zusammenhang auch das „Jahr der Kirchen für Migration“78 veranstaltet, dessen

70 Vgl. Internetquelle: ICMC.

71 Der „Welttag der Migranten und Flüchtlinge“ wurde 1914 von Benedikt XV. unter dem Eindruck des Ersten Weltkrieges von Papst Benedikt XV. eingeführt und ist seither ein kirchlicher Gedenktag. 2001 hat die UNO den 20. Juni als fixen Termin für dieses Gedenken festgelegt.

72 Vgl. Tomasi 2008, S. 520-537.

73 Vgl. ebd.

74 Vgl. Internetquellen: Deutsche Bischofskonferenz.

75 Es gibt freilich auch innerkirchliche Kritiker der kirchlichen „Flüchtlings- und Migrationspolitik“; ja, es lassen sich sogar rechtsextreme und rassistische Einstellungen unter Gläubigen finden: vgl. Strube 2015.

76 Vgl. Internetquellen: The Churches' Commission for Migrants.

77 Austria, Belgium, Cyprus, Czech Republic, Finland, France, Germany, Greece, Hungary, Italy, Norway, Romania, Slovakia, Spain, Sweden, Switzerland, The Netherlands, United Kingdom.

78 Siehe Internetquellen: Migration 2010. 
Projekte, Ideen und Vorschläge täglich an Relevanz gewinnen. Das „Central Committee of the Ecumenical Council of the Churches" in Genf (Schweiz) ist eine weitere ökumenische, international aktive Organisation im Einsatz für eine Kultur der Gastfreundschaft und Begegnung im Zusammenleben mit Flüchtlingen und Migranten. ${ }^{79}$ Bildungsprogramme, Gemeindearbeit, Entwicklung multikultureller Gottesdienste gehören zu der Fülle der Projekte. Im Jänner 2016 hat diese Organisation gemeinsam mit der UNICEF, der UNFPA und dem UNHCR eine internationale Konferenz zur Flüchtlingskrise veranstaltet und ein Konzept mit zahlreichen Lösungsvorschlägen verabschiedet, die vor allem dem politischen Kampf gegen die Ursachen von Flucht und Migration gewidmet sind. ${ }^{80}$

Auf die Fülle und Intensität des Einsatzes christlicher Hilfsorganisationen, Ordensgemeinschaften und Gemeinden auf nationaler und lokaler Ebene kann ich hier im Detail nicht eingehen; ohne sie wäre die Landkarte der europäischen Solidarität jedenfalls um einen unverzichtbaren und konstitutiven Teil ärmer. Im konkreten Einsatz für und im alltäglichen Zusammenleben mit schutzsuchenden Menschen wird der Glaube im Leben unzähliger Christen konkret. Religion ${ }^{81}$ kann im Kontext von Flucht und Migration ein wichtiger Teil der Lösung der anstehenden Herausforderungen sein.

Zugleich kann Religion selbstverständlich auch Teil des Problems sein; eine Wahrnehmung, die im öffentlichen Diskurs dominiert. Diese betrifft nicht allein die Fluchtursachen jener Menschen, die aus dem arabischen Raum nach Europa kommen, u. a. die Konflikte zwischen den verschiedenen islamischen Gruppierungen, die Vertreibung und Ermordung religiöser Minderheiten sowie die Gewalt gegen Christen, die auch in Flüchtlingslagern in Europa immer wieder anzutreffen ist. Dies betrifft auch keinesfalls nur „den Islam“, der im Diskurs um Flucht und Migration immer wieder als konflikt-, gewalt- und kriegserzeugende Ursache stigmatisiert oder als „Integrationshindernis“ beschrieben wird. Auf die Komplexität der Zusammenhänge zwischen Islam und Politik gehe ich hier aufgrund eines anderen Fokus des Beitrages jedoch nicht näher ein. Hingewiesen sei allerdings auf die „Religionisierung“ politischer Zusammenhänge: wenn der öffentliche und politische Diskurs vorschnell und undifferenziert „Religion“ zum Hauptproblem erklärt und die Ablehnung von Flüchtlingen und Migranten bzw. Schwierigkeiten mit ihnen mit „religiösen Unvereinbarkeiten“ erklärt.

Selbstverständlich ist der Islam - wie jede Religion - verpflichtet, seinen Beitrag zur Entstehung von Gewalt und Krieg zu reflektieren und Selbstkritik und Selbstaufklärung zu leisten. Aber Probleme im Feld von Flucht und Migration bestehen eben nicht nur auf Seiten des Islam, sondern auch des Christentums.

\footnotetext{
79 Vgl. Internetquellen: Documents of the Ecumenic Council.

80 Vgl. Internetquellen: Ökumenischer Rat der Kirchen.

81 Selbstverständlich sind auch andere Religionsgemeinschaften aktiv in der Flüchtlingshilfe tätig, deren Engagement hier aber nicht näher entfaltet wird.
} 
Als katholische Theologin plädiere ich dafür, mit der Kritik zuerst bei sich selbst zu beginnen, ehe man von den „Anderen“ Veränderungen einfordert. ${ }^{82}$

So finden sich auch im Bereich der Kirchen Personen, Gruppen und Institutionen, die rassistische Dynamiken und Prozesse fördern und lebensförderliche Lösungen im Bereich von Flucht und Migration blockieren oder zerstören. Erinnert sei hier an die Stellungnahme von Bischof László Kiss-Rigó, der die Flüchtlinge als , islamische Invasion ${ }^{“ 83}$ bezeichnete, die Ablehnung der Aufnahme von Flüchtlingen durch osteuropäische Bischöfe ${ }^{84}$, aber auch an autoritärrechtsextreme Einstellungen bei Katholiken in Westeuropa. ${ }^{85}$ Die Verbindung von Glaube und rassistisch gefärbtem Nationalismus findet sich nach wie vor in osteuropäischen katholischen und orthodoxen Kirchen. Schließlich hat auch die jahrzehntelange Migrationsblindheit christlicher Gemeinden und Theologien im deutschsprachigen Raum nicht nur den Migranten vor der eigenen Haustür keine praktische und theologische Aufmerksamkeit geschenkt, sondern sogar die anderssprachigen Diaspora-Gemeinden innerhalb der eigenen Kirchen ignoriert. Segregationstendenzen von Migrationsgemeinden und „Integrationsprobleme“ gibt es infolgedessen auch innerhalb der christlichen Kirchen, nicht nur bei muslimischen Gemeinden.

Soziologische Studien zeigen seit langem, dass Schwierigkeiten mit Minoritäten einerseits als deren Reaktion auf Erfahrungen des Ausschlusses und eines

82 Ich schließe mich hier der Ansicht des Schriftstellers Navid Kermani an, der in seiner Rede anlässlich der Verleihung des Friedenspreises des deutschen Buchhandels ebenso vorgeht und der Selbstkritik Vorrang gibt: „Die Liebe zum Eigenen - zur eigenen Kultur wie zum eigenen Land und genauso zur eigenen Person - erweist sich in der Selbstkritik. Die Liebe zum anderen - zu einer anderen Person, einer anderen Kultur und selbst zu einer anderen Religion - kann viel schwärmerischer, sie kann vorbehaltlos sein. Richtig, die Liebe zum anderen setzt die Liebe zu sich selbst voraus. (...) Die Selbstliebe hingegen muss, damit sie nicht der Gefahr des Narzissmus, des Selbstlobs, der Selbstgefälligkeit unterliegt, eine hadernde, zweifelnde, stets fragende sein." Siehe Internetquellen: Kermani, Navid. Eine ähnliche Hermeneutik schlägt übrigens im Rückgriff auf GS 44 Hans-Joachim Sander immer wieder vor, z. B. in der Frage nach dem Verhältnis von Religion und Gewalt: Indem man die Stärken „der Anderen“ als Ausgangspunkt der Begegnung wählt und sich mit ihnen identifiziert, werden die eigenen Schwächen bearbeitbar: „,Die anderen' sind nicht wie ,wir' und wir können deshalb deren Stärken als Basis aufgreifen, um unsere Schwächen zu überwinden. Dann ist es strukturell unmöglich, sich allein von der eigenen Religionsgemeinschaft her - dem ,wir - zu identifizieren. Wegen der eigenen Schwächen muss man nach den anderen verlangen, die nicht so sind wie ,wir'. Das hebt die Versuchung des Ressentiments auf und errichtet ein Bollwerk gegen eigene Gewaltbereitschaften." Vgl. Sander 2005, S. 115-124.

83 Siehe Internetquellen: „Ungarischer Bischof spricht von ,Invasion muslimischer Flüchtlinge“".

84 Vgl. Internetquellen: „Osteuropäische Bischöfe und die Flüchtlingsfrage“.

85 Vgl. Strube 2015. 
Mangels an Anerkennung und Partizipation verstanden werden können. Andererseits gründen sie in den „Stammesmentalitäten“ menschlicher Gemeinschaften, die um den Verlust ihrer Identitäten besorgt sind, wovon sich Minoritäten in der Regel stärker bedroht sehen, sobald sich diese in ihrer kulturellen und religiösen „Eigenart“ nicht ausreichend anerkannt fühlen. ${ }^{86}$ Ein Mangel an kommunikativem Austausch und geteiltem Alltagsleben, in deren Rahmen Gemeinsamkeiten entdeckt oder gemeinsam Werte entwickelt werden könnten, forciert sodann Segregationstendenzen und Exklusionsmechanismen. Religion als solche spielt bei solchen soziologischen Prozessen eine nachgereihte Rolle. Relevant wird sie insofern, als sie religiöse Begründungen für oder gegen das Zusammenleben kulturell und religiös Verschiedener bereitstellen kann. Sie kann zu Öffnung, Partizipation und Solidarität ermuntern oder aber Abgrenzung, identitäre Grenzsicherung oder fundamentalistische Einstellungen fördern, die den Vorstellungen von Wirklichkeit Vorrang geben vor dem Sich-Einlassen auf und dem Lernen von neuen Realitäten. Religion kann Inklusion fördern oder hemmen - jede Religion und sowohl die der Mehrheitsgesellschaft als auch die der Minoritäten.

Der jeweiligen Praxis religiöser Gemeinschaften im Kontext von Flucht und Migration liegen immer - explizit wie implizit - Wahrnehmungen und Deutungen der Wirklichkeit aus der Sicht des Glaubens zugrunde. Ebendiese bewusst zu machen und kritisch zu reflektieren, ist eine der zentralen Aufgaben theologischer Intellektualität.

\subsection{Theologisch-Intellektueller Beitrag}

Aber inwiefern kann theologische Intellektualität einen Beitrag leisten? Ja, kann sie das überhaupt, wo sie doch in den Augen vieler Zeitgenossen letztlich auf einem unbeweisbaren Glauben aufruht, der dem Wesen von Intellektualität zu widersprechen scheint? Und was kann sie zur Analyse von Stimmungen leisten, um die es mir hier geht? Wird es rund um das Thema „Gefühle“ intellektuell besehen nicht noch dubioser? Was bedeutet theologische Intellektualität?

\subsubsection{Kritische Reflexion}

Theologie versteht sich aus praktisch-theologischer Sicht als vernünftige, kritische Reflexion des Glaubens als Lebensform und der damit verbundenen theoretischen Inhalte. Der damit verbundenen Intellektualität geht es nicht darum, Lehren oder Weltanschauungen zu verkünden oder bestimmte Handlungsvorschriften zu machen. Vielmehr sollen die vorfindbaren Wahrnehmungen, Deutungen, Einstellungen und Praxisformen, die - hier im Feld von Flucht und Mi-

86 Z.B. Castles / Miller 3rd, rev. Edition 2003, S. 310 ff.; Atac / Rosenberger 2013; Schiffauer 2008. 
gration - kritisch unter die Lupe genommen werden. Dies geschieht auf der Basis sowohl der theologischen Tradition in Bibel und Kirche als auch sozialwissenschaftlicher Befunde, die in einen wechselseitig einander erschließenden, vertiefenden und kritischen Dialog gebracht werden. Der Glaube an Gott, der sich intellektuell nicht beweisen, wohl aber bezeugen und nachvollziehbar verstehen lernen lässt, spielt dabei „,nur“ insofern eine Rolle, als er in Form, Struktur und Inhalt als handlungsleitend explizit und reflex gemacht und einer (selbst-)kritischen Prüfung ebenso unterzogen wird wie der Kritik der Vernunft der Anderen, hier: der Sozialwissenschaften.

\subsubsection{Spiritualität denken: Fragen, Zweifeln, Sich-etwas-vorstellen, Erinnern und Transzendieren}

Praktisch bedeutet dies: Theologische Intellektualität wird in Bezug auf Flucht und Migration die zeitgenössischen Wahrnehmungen, Deutungen, Einstellungen und Praxisformen in diesem Feld zuerst be- und hinterfragen und mit jenen in einen Austausch bringen, die sich zu diesem Themenfeld in der Tradition finden. Insofern „der" Glaube als eine Sammlung durchaus heterogener theoretischer wie praktischer Antworten auf die zutiefst menschlichen Fragen nach dem Sinn und Ziel der Geschichte verstanden werden kann, geht es allem voran um die Frage nach dem Sinn und Ziel der Ereignisse im Kontext von Flucht und Migration. Was hat es mit der Ankunft der Flüchtlinge in Europa auf sich? Was bedeuten die damit verbundenen Herausforderungen für den Glauben, die Gläubigen und die Kirche? Erst daraus resultieren Vorschläge, was sodann zu tun wäre. Zuerst steht also die Sensibilisierung für die theologische Relevanz dieser Fragen im Zentrum - um sodann den Beitrag der christlichen Tradition für die Gegenwart fruchtbar zu machen.

Theologische Intellektualität lässt sich vielleicht gut mit jener Art des Denkens beschreiben, wie es Hannah Arendt beschrieben hat. ${ }^{87} \mathrm{Im}$ Unterschied zum "Wissen“ vollzieht sich Denken als Fragen und Zweifeln, als Unterscheiden, als sich-etwas-Vorstellen, als Erinnern und als Transzendieren sowie als nach-demSinn-Fragen. Insofern für Arendt das Denken eine aktive Tätigkeit des Geistes ist, hat es relationalen Charakter: Der Mensch bezieht sich darin geistig auf die Wirklichkeit. Für Arendt sind demnach Denken und Intellektualität eine Form der Spiritualität. ${ }^{88}$

Diese enge Verbindung von Denken und Spiritualität ist auch Kennzeichen theologischer Intellektualität. Spiritualität, verstanden als alltäglich gelebter Glaube, ist untrennbar mit Reflexion dessen verbunden, was Menschen erleben in der christlichen Tradition auch und gerade geschichtlich. Konkrete geschicht-

87 Vgl. Arendt ${ }^{2} 2002$, S. 9-240.

88 So ist für sie die Erfahrung der Denktätigkeit „wohl der eigentliche Ursprung unseres Begriffes der Spiritualität überhaupt, ohne Rücksicht auf die Form. “: Vgl. Arendt ${ }^{2} 2002$, S. 54. 
liche Ereignisse wurden und werden denkerisch zu Erfahrungen „verdichtet“, die in einem wechselseitigen Austausch zu Handlungen „gerinnen“ und vice versa neue Erfahrungen stiften. Dabei spielen im Bereich der Spiritualität Emotionen und Stimmungen eine fundamentale Rolle. Im Unterschied zur Romantik jedoch, die Emotionen nur als spontane und unmittelbare Gefühlswallungen wahrnehmen wollte, geht die christliche Tradition davon aus, dass diese Stimmungen auch im Denken, in Erfahrungen und Inhalten gründen, daher der Reflexion bedürfen und, vor allem: gebildet und geübt werden können ${ }^{89}$ Dies ist eine weitere Aufgabe theologischer Intellektualität.

\subsubsection{Unterscheidung, Macht- und Selbstkritik}

Ziel ist die Unterscheidung: widersprüchliche Perspektiven und Aspekte auf ein und dasselbe Phänomen zu entdecken und zu benennen, mögen sie auch schmerzvoll oder bedrohlich sein; sodann Deutungen und Argumente zu sammeln und abzuwägen, um zu Entscheidungen zu kommen, die dem Phänomen möglichst angemessen sind. In der christlichen Tradition steht dafür vor allem die geistliche Unterscheidung, wie sie Ignatius von Loyola begründet hat, um in den Ereignissen der Zeit den Willen Gottes angesichts konkreter Lebenssituationen zu erkunden. Aber auch in der philosophischen Tradition finden sich solche Anliegen. Michel Foucault beispielsweise spricht in diesem Zusammenhang von Parrhesia, wobei er bei diesem Unterscheidungsprozess vor allem das Verhältnis zwischen Macht und Wahrheit zum Thema macht. ${ }^{90}$ Insofern parrhesiastische Rede den Freimut bedeutet, die Wahrheit auch der politischen Macht gegenüber zu sagen, macht er die politische Verortung der geistlichen Unterscheidung bewusst. Denn „die Wahrheit“ wird gegenüber „dem Souverän“ geäußert, also dem jeweils herrschenden Machtkomplex, wodurch sich der Sprecher immer in Gefahr begibt. An ebendieser Selbst-Gefährdung erkenne man den Intellektuellen, der durch seine Unterscheidung vom sozialen Ausschluss bedroht ist. Diese machtkritische Aufgabe der Intellektualität findet sich quer durch die Philosophiegeschichte immer wieder. Erscheint die „Parrhesia“ - die freimütige Rede von der Paulus immer wieder spricht, so nicht in einem ganz neuen Licht?

Die Unterscheidung hat immer auch eine kritische Dimension. Dabei richtet sie sich allerdings in erster Linie an die eigene Gruppe, sei es die Familie, der „Stamm“, die „Nation“ - oder eben die eigene Religion. So war bereits Sokrates der Ansicht, dass es den Intellektuellen ausmache, die Grundannahmen der eigenen Gruppe im Namen allgemeingültiger Werte zu hinterfragen. In jüngerer Zeit waren es vor allem Hannah Arendt oder Michael Walzer, die die Aufgabe des Intellektuellen darin sahen, der eigenen Gruppe den Spiegel vorzuhalten bzw.

89 Zu erinnern ist hier z. B. an „Wüstenväter“ wie Evagrius Ponticus mit ihren spirituellen Übungen, die ganz wesentlich der Zivilisierung menschlicher Gefühle dienten oder die ,schola affectus“ der Jesuiten.

90 Vgl. Foucault / Pearson 1996. 
den sich selbst glorifizierenden Habitus von Gruppenzugehörigkeiten zu hinterfragen. ${ }^{91}$

\subsubsection{Religionskritik}

Ebendiese selbstkritische, auf (politische und gesellschaftliche) Gruppen bezogene Aufgabe der Intellektuellen bekommt im Kontext von Debatten rund um Flucht und Migration eine neue Bedeutung. Die Ankunft der Flüchtlinge würde nämlich so vorrangig ein Anlass zu Selbstreflexion und -kritik der Einheimischen. Interessant ist dies insofern, als auch theologische Intellektualität zuerst selbstkritischer Reflexion - auch und gerade der eigenen Gemeinschaft gegenüber verpflichtet ist. Die „Erfindung“ der Selbstkritik - vor allem gegenüber der eigenen Religion, die doch immer auch das eigene Handeln legitimieren soll - hat ihren Ursprung in der jüdischen Tradition. Religionskritik beginnt mit der Unterscheidung von religiöser und politischer Macht im Zuge des Exodus und zieht sich durch das gesamte Alte Testament. Insbesondere in der prophetischen Literatur bekommt sie ihre Gestalt als Selbstkritik. Theologische Intellektualität als (Selbst)Kritik von Politik und Religion gehört demnach ebenfalls zu christlicher Spiritualität und zeigt deren enge Verbundenheit mit politischen Kontexten. ${ }^{92}$

\section{Der intellektuelle Beitrag - ein Versuch}

\subsection{Migrationsphänomene als Ursprungsorte theologischer Intellektualität}

Im Kontext von Flucht und Migration bekommt eine so verstandene theologische Intellektualität paradigmatische Relevanz. Einigen Facetten habe ich in diesem Beitrag bereits nachzukommen versucht. Im Folgenden konzentriere ich mich auf die eingangs gestellte Frage, welchen intellektuellen Beitrag eine theologische Perspektive auf die Grundstimmungen Freude und Hoffnung, Trauer und Angst leisten kann. Dabei stelle ich die bibeltheologischen Grundlagen dieser Stimmungen ins Zentrum meiner Überlegungen: Was gibt aus deren Sicht Anlass zu Freude und Hoffnung? Was unterstützt im Umgang mit Trauer und Angst?

91 Diese Hinweise verdanke ich: Illouz 2015, S. 7ff; S. 19-45.

92 Auf die historische Tatsache, dass die christlichen Kirchen dieses jüdische Erbe über Jahrhunderte hinweg vergessen, ausgesperrt und sogar dagegen gehandelt haben, kann ich hier nicht erörtern, muss es aber erwähnen. Es waren immer nur einzelne Personen oder Gemeinschaften, die es wieder in Erinnerung gerufen haben. In verschiedenen theologischen Strömungen - nicht zuletzt von Befreiungstheologien, feministischen oder schwarzen sowie postkolonialen Theologien ist es wieder aufgegriffen worden. Nicht zuletzt sind weder das Leben und Sterben Jesu noch die Texte des Neuen Testaments ohne den zeitgenössischen politischen Kontext zu verstehen. 
Dass es dabei nicht um religiöse Induktion „positiver Gefühle“ oder Optimismus im Horizont von Krisen gehen kann, ist bereits deutlich geworden. Christlich begründete Hoffnung und Freude dienen nicht dazu, von der Dramatik einer Situation abzulenken oder sie schönzureden. Dann hätten sie opiate Funktion. Vielmehr eröffnet eine Relektüre der biblischen Texte im Lichte der aktuellen Herausforderungen neue Perspektiven sowohl auf die Gegenwart von Flucht und Migration als auch auf die Texte der Heiligen Schrift.

Fast von der ersten Seite der Heiligen Schrift an lässt sich die fundamentale spirituelle und theologische Bedeutung von Erfahrungen im Kontext von Fluchtund Migrationsphänomenen erkennen. Die biblischen Grunderfahrungen von Hoffnung und Freude entwachsen im Alten Testament wesentlich der Auseinandersetzung mit Exil und Diaspora, Aufbruch und Vertreibung, Fremdheit, Armut und Ungerechtigkeit. Freude und Hoffnung entstehen nicht innerlich im zeitlosen Raum, sondern sind an konkrete Migrationserfahrungen gebunden. ${ }^{93}$ Diese wurden als Erkenntnisorte Gottes wahr- und ernstgenommen. So lässt sich z.B. sogar die Verfasstheit des Menschen, wie sie die Genesis beschreibt, als Vertreibung aus der ursprünglichen Heimat bei Gott beschreiben.

Selbstverständlich kann man die Migrationserfahrungen der Bibel nicht unmittelbar in die Gegenwart übertragen, zu verschieden sind ökonomischer, politischer, sozialer, kultureller und religiöser Kontext. Aber es ist doch bemerkenswert, dass die Suche nach den inhaltlichen Quellen von Freude und Hoffnung, Trauer und Angst just in den Kontext der „Migrationsgeschichte“ des Volkes Israel führt, wie sie im Alten Testament beschrieben wird. So lassen sich für die Gegenwart durchaus einige relevante Parameter des intellektuellen Umgangs mit Flucht und Migration ausmachen, die für die Gegenwart wegweisend sein könnten.

Nun hat die bibelwissenschaftliche Forschung gezeigt, dass die Ereignisse, wie sie in den Schriften des Alten Testaments erzählt werden, so nicht stattgefunden haben. Je mehr man entsprechende historische Forschung studiert, umso größer wird die Differenz zwischen dem Erzählten und dem, was sich mit mehr oder weniger hoher Wahrscheinlichkeit ereignet hat. Umso interessanter und aktueller wird dann aber, wie die Verfasser der Schriften mit diesen Ereignissen umgegangen sind, sie gedeutet haben und welche Handlungskonsequenzen für die Zukunft sie daraus gezogen haben. Auf dieses „Wie“ möchte ich die Aufmerksamkeit richten.

So entstehen die maßgeblichen Texte des Alten Testaments in der theologischen Reflexion katastrophischer Ereignisse, in denen für das Volk Israel alles am Ende zu sein scheint: die eigene Identität, das Fortbestehen und die Zukunft des Volkes, jeglicher Sinn der Geschichte, ja, sogar die Existenz selbst. Es sind Migrationsphänomene, die zu diesen Situationen größtmöglicher Existenzangst führen: Aufbruch, Deportation und Vertreibung, Exil und Diaspora und der 
Auszug aus Ägypten in eine völlig ungewisse Zukunft, Wanderung durch die Wüste inklusive. Ebendiese Angst wird durch intellektuelle Reflexion theologisch zu einer Erfahrung transformiert: Die Ereignisse werden im Nachhinein gelesen als Befreiung und Rettung, als Entstehung neuen Lebens und Sinns. Angst wird geistig umgeformt in Hoffnung auf Zukunft und Freude am Sinn, der neu entsteht. Jene Wirklichkeit, die diesen Transformationsprozess von ohnmächtiger Angst zu lebensschaffender Hoffnung ermöglicht, der sich sowohl innerlich als auch äußerlich, d.h. konkret geschichtlich manifestiert, wird „Gott“ genannt. Durch das Be-Denken der Ereignisse wird den Katastrophen Sinn und Bedeutung verliehen: Fragen nach deren Sinn, Selbstkritik, Erinnerungen an bisher Widerfahrenes, die als hermeneutische Quellen herangezogen werden, Transzendieren der unmittelbaren Ereignisse auf deren inneren Sinn, Kritik an nicht zuletzt dem eigenen Umgang mit Macht und Religion. Dieser Denk-Prozess lässt neue Hoffnung schöpfen - begründete Hoffnung.

Denn die Geschichte wiederholt sich in gewissem Sinn immer wieder: Nach jeder Katastrophe geht das Leben weiter. Die Erzählung, die dabei entsteht, ist freilich keine lineare oder gar bruchlose Geschichtstheologie des „Alles wird wieder gut", die die unzähligen Opfer dieser Katastrophen ausblendet oder verleugnet. Im Gegenteil: Täter und Opfer werden benannt, Strukturen und Prozesse der Gewalt dargestellt und selbstkritisch schonungslos offengelegt. Dafür sorgen u. a. nicht nur die Fülle der literarischen Formen in der Schrift - Erzählungen, Gebete, Dichtung, Gesetze u.v.m. - sondern auch die Heterogenität der Deutungen, die nicht gleichgeschaltet werden. Leid, Not, Gewalt, das Böse wird beim Namen genannt. Brüche und offene Fragen bleiben ebenso bestehen. Aber eben auch die durchgehende Beziehung zwischen Gott und seinem Volk, die den „roten Faden“ dazu bietet: schwierig, streitbar, aber von Gottes Seite aus immer treu. Diese Treue ist keine „Lehre“, sie wird zur geschichtlichen Erfahrung, auf die in Katastrophenzeiten immer wieder zurückgegriffen werden kann: Weil es schon einmal weitergegangen ist, wird es wieder weitergehen.$^{94}$ Dies geschieht durch Erinnerung als Vergegenwärtigung der Vergangenheit in ihrer Bedeutung für die Zukunft, wobei diese den Primat hat. Die Erinnerung an die Zukunft eröffnet Hoffnung.

$\mathrm{Zu}$ dieser Beziehungs-geschichte gehört untrennbar auch die Umkehr auf Seiten des Menschen - die teschuwa: Reue, Trauer, Versöhnung. Diese Umkehr führt aus Angst und Verzweiflung und ebnet den Weg zu neuer Hoffnung, weil so - nur so - Zukunft wieder in den Blick kommen kann. Insbesondere die Psalmen geben eindrücklichen Einblick in diese „Gefühlsarbeit“ und „Gefühlsschulung“, die die Geschichtsdeutung Israels beständig begleitet.

Dass „Gott“, der auf diesen Wegen durch all diese Katastrophen als treuer Begleiter erfahren wird, keinen Namen hat, mit dem man ihn festmachen könnte,

$94 \mathrm{Zu}$ dieser - weder linearen noch zyklischen - Zeitauffassung vgl. Shulamit Bruckstein 2007, S. $40 \mathrm{ff}$. 
ist dabei nur folgerichtig. Das Einzige, worauf sich das Volk verlassen kann, ist die ständige und unvorhersehbare Veränderung: auch die der scheinbar hoffnungslosesten Situationen. Wenn Michel de Certau den Gottesnamen JHWH - zumeist übersetzt mit „Ich bin der, der ich bin und sein werde“, „Ich bin der Ich bin da“ angesichts des brennenden Dornbusches, in dem alle Namen Gottes verbrennen, nur seine Präsenz nicht, mit „Ich habe keinen Namen als das, was Dich aufbrechen lässt“95 übersetzt, bekommt dieser „Nicht-Name“, der auf die Unverfügbarkeit Gottes verweist, im Licht der Migrationserfahrungen nochmals eine ganz besondere Bedeutung: als Gottes Präsenz in allen, insbesondere katastrophischen Situationen, deren Ausgang niemand vorhersehen kann.

\subsection{Migrationserfahrung als Lernort}

Migrationsphänomene kommen in vielen biblischen Texten in ihrer ganzen Dramatik und Mehrdeutigkeit konkret zur Sprache. Sie werden gerade nicht religiös oder theologisch idealisiert oder überhöht. Sie sind zuerst ein Übel und eine Katastrophe. Trotzdem - oder vielleicht gerade deshalb, weil sie als solche wahr- und ernstgenommen werden - werden sie zum zentralen Ort für Lernerfahrungen mit Gott. Migration wird daher ganz nüchtern als Zerstörung von Leben und Verlust von Heimat mit all den damit verbundenen Stimmungen erfahren: als „Fluch“. Sie wird in ihrer Tragik nicht schön gemalt. Zugleich werden die damit verbundenen Erfahrungen von Angst und Verzweiflung durch Intellektualität geistig transformiert. So wird Migration zum Ort, an dem Neues zu lernen ist: über sich selbst, über die Menschen, über die Welt und Gott.

In diesem Kontext von Migration entwickelt Israel seine - in der Schrift durchaus heterogenen - Vorstellungen über gutes und gerechtes Zusammenleben, in dessen Zentrum aber immer die Sorge um eine gerechte Gesellschaft und einen humanen Umgang mit „Fremden“ stehen. Es ist dieser Entstehungskontext, der dazu führt, dass in den Sozialordnungen des Alten Testaments Gerechtigkeit gegenüber den Marginalisierten und Exkludierten - Witwen und Waisen, Armen und Fremden - eine Schlüsselrolle spielt. Offenbar sind die Verfasser aufgrund der eigenen Erfahrung als Fremde (vgl. Lev 19,34) zu der Erkenntnis gekommen, dass sich die Sorge eines Gemeinwesens allem voran an der Verantwortung für diese Gruppen zu orientieren hat. So sollen erneute Katastrophen vermieden werden. Unrecht, Ungleichheit und Ungerechtigkeit und die daraus resultierende Verarmung von Bevölkerungsgruppen werden als Ursache bei der Entstehung politischer Katastrophen gesehen: nicht die Fremden als solche. ${ }^{96}$ Vielmehr schließen die Autoren aus der Erfahrung, selbst Fremde

95 Certeau 2010, S. 289.

96 Wohl gibt es auch fremdenfeindliche Texte im Alten Testament, aber es ist nicht die Fremdheit der Feinde das primäre Problem, sondern die jeweilige politische oder 
gewesen zu sein, dass diese Gruppe speziellen Schutzes bedarf, insofern sie von Armut und Gewalt in besonderer Weise bedroht ist.

Ebenso selbstkritisch kommen die Verfasser zu dem Schluss, dass das Versagen der politisch Verantwortlichen in der Verantwortung für Recht und Gerechtigkeit eine maßgebliche Ursache für die Katastrophe des Exils war. ${ }^{97}$ So bekommen Sozialgesetze - einmalig in der Geschichte des Orients - den Charakter politischen Rechtes und obliegen nicht mehr der Moralität und damit der Willkür der Machthaber. ${ }^{98}$ Sie haben gleichsam ,göttlichen“ Status. Dies gilt ebenso für den Schutz der Fremden. In diesem Sinn wird Migration zum „Segen“: Sie wird zum Ort der Gotteserkenntnis und verbindet sich zuinnerst mit dem Erkennen und Erlernen menschengerechter Sozialordnungen. Sie transformiert das Leid in neues Leben. Hier wurzelt auch die Möglichkeit zur Freude: angesichts der Errettung, der neuen Lebenschancen, der Erkenntnis des Willens Gottes und der Gemeinschaft, in der dies alles erfahren, durchdacht und im alltäglichen Leben eingeübt werden kann.

\subsection{Migrationshermeneutik auch im Neuen Testament}

Auch die Evangelien entstehen im Kontext katastrophischer Erfahrungen: der Tod des Jesus von Nazareth, die Zerstörung des Tempels 70 n. Chr., die Verfolgung und Ermordung tausender Judenchristen durch das Imperium Romanum, die Existenz als verfolgte Diasporagemeinden. ${ }^{99}$ All diese Ereignisse haben für die junge Gemeinschaft der Judenchristen zunächst das Ende aller Hoffnungen auf Zukunft bedeutet und die Zerstörung der Gemeinschaft angekündigt. So entstehen auch zentrale Texte des Neuen Testaments in einem Geschichtsraum, der von Angst und Hoffnungslosigkeit gekennzeichnet ist. Erneut bietet der Rückgriff auf die Erinnerung der eigenen Tradition, die den jungen Gemeinden als heute „Altes Testament“ genannte Schriften vorlagen, Möglichkeiten, die Ereignisse zu deuten und Angst in Hoffnung und Handlungsorientierung für die Zukunft zu transformieren. Die Auferstehung des Jesus von Nazareth schreibt die Geschichte Gottes mit seinem Volk fort, der nicht zulässt, dass das Böse und die Gewalt, Leid und Tod das letzte Wort haben.

Zum Verständnis des inneren Sinnes der prekären Lebenssituation der jungen Gemeinden werden auch migrationstheologische Motive herangezogen und in neuem Kontext solcherart fruchtbar. Der Verlust von Heimat - nunmehr: des Tempels, der auch für Judenchristen zentraler Kultort war - bedeutet nicht das

ökonomische Übermacht, die Israels Identität oder Existenz bedrohen, vgl. Schwienhorst Schönberger 1990, S. 108-117.

97 Vgl. dazu das umfassende Werk von Lohfink und Braulik zum Deuteronomium.

98 Vgl. Assmann 2015.

99 Vgl. z. B. Verkaamp 2012. 
Ende der neuen Gemeinschaft. Unterdrückung und Vertreibung, selbst die vielen Toten und Ermordeten, bedeuten nicht das Ende der Geschichte. Weil Gott sein Volk immer wieder aus Katastrophen geführt hat, wird er es wieder tun. Auch die späteren Schriften sesshafter Gemeinden werden die Schwierigkeiten der Diaspora, in der sie leben, mithilfe migratorischer Motive ver- und bestehen, wenn sich die Gläubigen als Fremde in der Welt bezeichnen, die ihre Heimat bei Gott haben (Hebr 11,13; 1 Petr 2,11).

So reihen sich auch die Texte des Neuen Testaments in die jüdische Tradition ein, indem sie diese im Horizont der Gegenwart reinterpretieren, fruchtbar machen und weiterschreiben. Immer wieder wird es dabei möglich, die eigene Angst in Trauer und sodann Hoffnung und Freude zu transformieren.

\subsection{Biblische Migrationstheologie für die Gegenwart}

Stehen hier nicht - formal und inhaltlich - wichtige Deutungstraditionen zur Verfügung, die nicht nur die Gläubigen, sondern auch die Gesellschaft bereichern könnten? Ein bibeltheologischer Zugang kann ermöglichen, Flucht und Migration in ihrem „Fluch“ ernst zu nehmen und, wie die biblischen Autoren, solide Ursachenanalyse zu betreiben. Zugleich lässt sich lernen, dass ein defizitorientierter Blick nicht in die Zukunft führen kann. Biblische Migrationstheologie ermöglicht eine Sicht auf die aktuellen Phänomene, die diesen einen Sinn unterstellen und „ressourcenorientierte“ Narrative fördern, sodass Flucht und Migration zum „Segen“ werden können, d.h. neues Leben ermöglichen. Das geschieht freilich nicht automatisch, sondern bedarf der intellektuellen Auseinandersetzung, der geistigen Transformation und des engagierten Handelns, wie die Bibel erzählt.

Bibeltheologisch begründete Intellektualität nimmt die Ängste ernst, ermutigt aber zugleich zu Denk- und Handlungsoptionen, wie diese in Trauer zu verwandeln sind. Sie fordert zum Aufbruch in die Zukunft auf, mag sie auch ungewiss sein. Im Zentrum steht dabei wesentlich der Hinweis auf die Wichtigkeit, eine sozial gerecht geordnete Gesellschaft zu bauen, die ihr Maß an den Marginalisierten nimmt. Nicht die Fremden sind die Bedrohung, sondern die geballte ökonomische und politische Macht von Menschen über Menschen sowie die Erzeugung von Armut und Ausschluss. Die Schrift zeigt, dass und wie Migration ein Lernort werden kann auf dem Weg der Menschheit zu einer je humaneren, gerechteren, friedlicheren Welt und einem guten Zusammenleben. Sie ermutigt dazu, sich auf die Suche nach dem Sinn einzulassen, der möglicherweise in den aktuellen Ereignissen liegt.

Worin dieser für heute konkret liegt, sagen die Texte der Heiligen Schrift freilich ebenso wenig wie sie keine konkreten politischen Aktionen benennen. Dies ist die Aufgabe der Gegenwart. Dazu bedarf es der soliden Kenntnis der aktuellen Situation. Der Sinn, der hier bereitliegt, bedarf also der Mitgestaltung 
der Menschen, sonst kann er sich nicht zeigen. Die Hoffnung, die gefördert wird, bietet keine Sicherheit. Aber immerhin ist es - vor allem Juden - immer wieder gelungen, mörderischen Zeiten nicht das entscheidende Wort über den Sinn der Geschichte zu lassen. Bibeltheologische Intellektualität eröffnet Perspektiven, die der Suche nach Lösungen Kraft und Zuversicht verleihen können. Sie formuliert spirituell wie politisch zentrale Eckpfeiler, die im Licht der Gegenwart neu belebt werden können. Sie formuliert gute und nachvollziehbare Gründe, an denen das Handeln sich orientieren kann. So werden ja nicht wenige der spirituellen und sozialpolitischen Erkenntnisse des Alten Testaments von der modernen Sozialwissenschaft belegt: wie z.B. die psychologische Verbindung von Angst, Trauer, Freude und Hoffnung, der (sozial)psychologische Zusammenhang von generationaler Erinnerung, Schuld und politischen Fehlentwicklungen oder die Bedeutung von Inklusion und Partizipation im Zusammenleben mit Fremden.

An dieser Stelle sei vermerkt, dass die „Botschaft“ der Schrift sich im Kontext von Flucht und Migration zuerst an Flüchtlinge und Migranten gerichtet hat und richtet. Die Texte bezeugen, dass „Gott“ - also die Veränderungsdynamik zum Guten hin sowie der innere Sinn der Geschichte - zuerst und konsequent auf der Seite jener steht, die aus Armut, Knechtschaft und Unterdrückung ausziehen. Deren Angst und Trauer haben Vorrang, ihnen sind Hoffnung und Freude zuerst zugesagt.

Dies wird der Mehrheit der Sesshaften möglicherweise nicht gefallen, weshalb die christliche Theologie in den reichen Ländern der Erde ja bis heute vielfach einen Abstraktionsgrad und eine Lebensferne hat, die den konkreten katastrophischen Entstehungskontext der Gründungstexte „vergessen“ resp. ausblenden lässt. Die Ankunft der Flüchtlinge macht dies schrittweise unmöglich, zu frappant sind die Ähnlichkeiten.

Haben die migrationstheologischen Motive der Bibel daher keine Bedeutung für sesshafte Europäer - was ja manche Katholiken auch behaupten, die das Engagement der Kirchen und „Gutmenschen“ für Flüchtlinge kritisieren?

Ich sehe die Bedeutung der biblischen Migrationstheologie für die Sesshaften vor allem in dem geschichtstheologischen Licht, das sie auf die Gegenwart werfen. Dieses ermöglicht insofern einen Narrativ, der in Migranten und Flüchtlingen weniger ein Problem sieht als vielmehr eine ausgezeichnete Möglichkeit bietet, Migration als Lernort für Europa zu begreifen. Flucht und Migration ermöglichen Selbstkritik der eigenen europäischen Lebensverhältnisse. Sie eröffnen Chancen, Menschlichkeit, Gerechtigkeit sowie Zusammenleben vertieft zu lernen und können solcherart auch einen Prozess der Befreiung der Sesshaften einleiten - hin zu mehr Freiheit und Freude in und mit dem Leben.

Das verbindet sich natürlich mit einer Menge Arbeit und Anstrengung, vor allem beim kreativen Entwickeln politischer Lösungen. Diese aber können wenn Migration und Flucht im Lichte des biblischen Narrativs interpretiert werden - nicht zu Abgrenzung und Abschottung Europas führen („,Flüchtlingsabwehr" nennt man dies neuerdings), sondern werden solidarisches Teilen för- 
dern und den abstrakten Glauben an „die Einheit der Menschheit“ mit konkreter Erfahrung durch das alltägliche Zusammenleben sättigen. Flucht und Migration sind die globalhistorische Chance zu lernen, dass die Menschheit eine ist und alle Menschen einander benötigen. Theologisch formuliert lässt sich dabei entdecken, dass in dem Sich-Einlassen auf die damit verbundenen konkreten Veränderungen zwar Angst und Trauer unvermeidlich sind, aus ihnen aber Hoffnung und Freude wachsen kann. Die Ursache dieser Transformation nennt der Glaube „Gott“. Migrantinnen und Flüchtlinge sind in diesem Sinn Geschenke. Wie Papst Franziskus es ausdrückt: „Ihr werdet als Problem behandelt und seid in Wirklichkeit ein Geschenk." 100

\subsection{Drei exemplarische bibeltheologische Beiträge}

\subsubsection{Eine ,Große Erzählung““}

Guten Grundes hat die Postmoderne im Anschluss an die politischen und religiös inszenierten Totalitarismen des 20. Jahrhunderts und deren katastrophische Folgen die „Großen Erzählungen“ desavouiert, die Sinn und Ziel der Geschichte festgelegt haben, Durchführungsprogramm mit Menschenvernichtung inklusive. Die Unterwerfung und Dienstbarmachung von Menschen im Namen einer Ideologie, die ein partikulares Interesse absolut gesetzt hat, sollte damit zu Ende sein.

Sind die Millionen Flüchtlinge, Vertriebenen, Armutsmigranten nicht ein Hinweis, das dem nicht so sein kann?

Und: Sind damit auch die Fragen nach einem Sinn und Ziel von Geschichte endgültig erledigt?

Löst der Verzicht auf diese Fragen die Probleme des Bösen und der Gewalt?

Kommen Menschen tatsächlich ohne „Große Erzählungen“ aus?

Die zeitgenössische globale Situation lässt mich dies ebenso bezweifeln wie die rechtspopulistischen und -extremen politischen „Antworten“, die im Horizont von Flucht und Migration wieder ihre Häupter erheben und auf die neuartigen Herausforderungen des 21. Jahrhunderts mit den Nationalismen und Rassismen des 19. und 20. Jahrhunderts reagieren.

Könnte nicht die „Große Erzählung“, wie sie die Bibel erzählt, einen Beitrag leisten, über diese Fragen neu nachzudenken?

Gerade die Art und Weise, wie die Frage nach Sinn und Ziel der Geschichte bibeltheologisch reflektiert wird, scheint mir auf paradoxe Art und Weise Perspektiven zu eröffnen. Denn die Fülle und Verschiedenheit der Texte reagiert auf die möglicherweise anthropologische Notwendigkeit einer „Großen Erzählung“ ebenso wie sie die historisch bekannten ideologischen Konkretionen inhaltlich 
unterläuft. ${ }^{101}$ Die „Große Erzählung“ der Bibel ermöglicht es nämlich gerade nicht, einen endgültigen Sinn oder ein für alle Zeiten definiertes Ziel zu definieren, geschweige denn eine spezifische „Methode“ zu deren Herstellung zu identifizieren. Es sei denn, man liest die Schrift fundamentalistisch und verwechselt deren Vorstellungen, Bilder, Erzählungen mit der beschriebenen Wirklichkeit und nützt sie als „Bedienungsanleitung“.

Erzählt und beschrieben werden keine Ideologien, sondern Prozesse zwischenmenschlichen Zusammenlebens sowie die Beziehung zu einer Wirklichkeit, die sich jeder endgültigen Benennbarkeit entzieht. Dies geschieht zudem in einer in den Texten nicht-homogenisierten, widersprüchlichen, vieldeutigen Weise, die zur je neuen Auslegung „,Zwingt“. Die „Große Erzählung“ der biblischen Texte ist plural und hält bewusst auch einander widerstreitende Erfahrungen und Deutungen in Erinnerung, um die Notwendigkeit des Fragens und Interpretierens offen zu halten und Menschen gerade nicht dazu zu zwingen, sich auf eine Idee zu einigen oder sich dieser gar zu unterwerfen. ${ }^{102}$ Die Fülle und Verschiedenheit der Erfahrungen soll erinnert werden.

Gewiss ist dabei einzig eine auf Zukunft hin offene ständige Transformation der Geschichte, deren Gestaltung in die Verantwortung der Menschen übergeben wird. Dazu werden ethische „Weg-Weiser“ wie Pflöcke eingeschlagen. Diese sind jedoch nicht idealistisch entwickelt, sondern durch die Katastrophen der (Migrations)Geschichte hindurch der Wirklichkeit abgerungen und solcherart erfahrungsgesättigt. Sie dürfen und müssen daher auch in Zukunft im Kontext der jeweiligen Gegenwartsherausforderungen weiterentwickelt werden. Sinn und Ziel sind materialiter nicht festgelegt, sondern obliegen der freien Gestaltung durch die Menschheit.

Will man die „innere“ Dynamik dieser Geschichte beschreiben, ließe sich von einer Geschichte sprechen, in der Menschen von allem befreit werden bzw. sich befreien, was ihre Beziehungen untereinander, zum Kosmos und zu dem, was sie als göttliche Wirklichkeit erleben, einschränkt, beschädigt und zerstört - hin zu einem erfüllten Leben miteinander und mit Gott. Was die christliche Tradition „Heilsgeschichte" nennt, ließe sich sodann als Befreiungsgeschichte erkennen. Innere und äußere Befreiung lassen sich dabei unterscheiden, aber nicht trennen.

Befreit werden Menschen von all ihren Idolatrien, die sie irdische Wirklichkeiten anbeten und sich ihnen unterwerfen lassen, wozu auch alle Vorstellungen

101 Was nicht bedeutet, dass nicht auch die Bibel für politisch-ideologische Interessen benützt wurde und wird.

102 Davon berichtet bereits die Erzählung vom Turmbau zu Babel (Gen 11), in der Gott selbst totalitäre Uniformisierungspläne der Menschen scheitern lässt und mit der „Sprachenverwirrung“ jene Vielfalt und Fremdheit der Menschen untereinander schafft, die diese dazu zwingt, miteinander in Kommunikation zu treten und einander verstehen zu lernen, anstelle sich einem gemeinsamen Projekt zu unterwerfen. Vgl. Ebach 2008, S. 39-58. 
von Gott gehören, mögen diese noch so fromm scheinen - hin zum ,aufrechten Gang" und einer Beziehung zu einem Gott, der sich jeder Fixierung entzieht. Sie werden aufgefordert, sich auf einen nach vorne hin offenen Prozess einzulassen, bei dem ihnen die Begleitung durch eine göttliche Wirklichkeit zugesagt ist und das Versprechen auf neue Heimat (vgl. Abraham, Gen 12,1-9). Befreit werden sie aus der Sklaverei politischer und religiöser Hegemonien, vermittels derer Menschen über Menschen herrschen und so unterdrückerische Verhältnisse zwischen diesen schaffen (vgl. Exodus). Stattdessen lernen sie, wie man eigenverantwortlich ein egalitäres, gerechtes Gemeinwesen aufbaut und Gott auf rechte Weise verehrt (vgl. Sinai-Bund). In diesem Gemeinwesen soll es per Gesetz keine Armen mehr geben; und für die Fremden wird eine im Orient einzigartige, Gesetzgebung entwickelt. ${ }^{103}$ Auf diese Weise soll die Freiheit der Menschen geschützt und gefördert werden. Der Gott, den die Autoren beschreiben, möchte freie Gesprächspartner.

Der Preis dieser Freiheit ist der Verlust jeglicher absoluten Sicherheit und die daraus resultierende Angst, die das Einfallstor der Sünde und des Bösen darstellt (vgl. bereits Adam, Gen 3,10). Diese fundamentale Daseinsangst gehört zum Mensch-sein. Sie kann nicht durch politische Projekte oder Psychotherapie beseitigt werden. Heilsam gegen die Angst ist Beziehung und Gemeinschaft. Die Schrift schildert die Liebe in all ihren Spielarten und entwirft ein der tätigen Liebe verpflichtetes Ethos des Miteinander-Lebens und Füreinander-Einstehens, das sich im Alten wie im Neuen Testament im Gebot der Gottes- und Nächstenliebe verdichtet. Es bedarf auch der inneren Befreiung von Angst. Die Bibel erzählt immer wieder von der Befreiung von „Dämonen“, d. h. von allen selbst-erzeugten (inneren) lebensfeindlichen Mächten und Dynamiken, die den Menschen in Besitz nehmen und unfrei machen. Nicht zuletzt entwickelt sich der Glaube an eine Auferweckung der Toten; denn der biblisch beschriebene Gott, der das Leben fördert, „muss“ auch stärker als der Tod sein. ${ }^{104}$ So wird auch letzerem die Macht genommen, über Menschen zu herrschen. Aus christlicher Sicht ist dies in der Auferstehung von Jesus Christus Wirklichkeit geworden.

Dieses „Gesamtpaket“ eröffnet eine „Große Erzählung“ paradoxer Art. Es geht nun nämlich nicht mehr darum, dass sich Menschen einer von einem „Gott“ hieße er auch Hitler oder Stalin - vorgegebenen Idee unterordnen und diese zu erreichen trachten. Vielmehr ereignet sich diese „Große Erzählung“ in den vielen „kleinen Erzählungen“ konkreter Menschen, die sich auf eine solche Dynamik des „Unterwegs-Seins“ einlassen und so selbst den Sinn der Geschichte schreiben: widersprüchlich, konfliktiv, mit unzähligen Brüchen, Scheitern und Fragezeichen. Denn die „Große Erzählung“ ist in der Bibel eine, nach der immer wieder gefragt, die erhofft, ersehnt, erwartet und erbetet wird. Ihr Sinn steht nicht ein für alle Mal fest. Ihre Gestaltung obliegt der Mitverantwortung aller und jedes ein-

103 Vgl. Assmann 2015; Braulik 2015, S. 563-576.

104 Vgl. Lapide 2010. 
zelnen Menschen. Die damit verbundene Fülle und Vielfalt vieler kleiner Erzählungen ist - paradox formuliert - das, was man theologisch den „Plan Gottes“ nennen könnte, dessen Beitrag in der treuen Begleitung besteht, auf die er sich sogar vertraglich, d.h. in Bünden - festgelegt hat sowie in seiner Vorsehung, i.e. Fürsorge.

Das „Ziel“ dieses Planes ist die Befreiung der Menschheit. Die „Große Erzählung" ist dabei von Beginn an universal-menschheitlich ausgerichtet. Schritt für Schritt lernen die Verfasser der Schriften, dass ihre Erfahrungen für alle Menschen von Relevanz sind und sie diese allen Menschen zugänglich machen sollen. Immer wieder wird neu nach dem Sinn der Geschichte und der eigenen Rolle darin gefragt. In unzähligen Erzählungen wird die „Strategie“ dieses Planes beschrieben. Es sind nicht die „Großen Helden“, die die zentralen Weichen für die Zukunft stellen, sondern konkrete, einzelne, fehlerhafte, sogar schuldig werdende Menschen. Lange Namenslisten belegen, dass jeder einzelne Mensch in dieser Freiheitsgeschichte eine Aufgabe hat. Die Geschichte folgt also gerade keinem generalstabsmäßigen Plan, sondern ist „ganz normalen Menschen“ anvertraut. Erfahrungen der Freude des Zusammenlebens gerinnen zu Bildern einer Zukunft, die die Hoffnung wachhalten, dass in der Zukunft alle Menschen in der Verschiedenheit ihrer Herkunft, Kultur, Religion in Friede und Gerechtigkeit miteinander leben werden (vgl. Wallfahrt der Völker zum Zion Jes 2, 2; 60, , Mich 4, 1; Offb 20,21-24; das „Haus des Gebetes für alle Völker“ Jes 56, 6-8; das Pfingstereignis Apg 2; die Versöhnung von Juden und Heiden Eph 2, 14 ; die Überwindung aller sexistischen, rassistischen, religiösen Diskriminierungen Gal 3,28; Kol 3,10-11).

Diese Zukunftsbilder sind keine Visionen oder Zukunftsvoraussagungen, sondern Versprechen und Verheißungen. Sie beschreiben, wie dieses Zusammenleben aussehen könnte, verdeutlichen aber aufgrund ihrer Form, dass deren Verwirklichung von der Gestaltung menschlicher Beziehungen abhängig ist. Versprechen sind keine Garantien, sondern bedürfen der Treue und darin der Bereitschaft, auf neue Herausforderungen neu zu reagieren. Versprechen sind fragil, man ,glaubt" nicht an sie, sondern lebt sie. Verheißungen sind keine Ideale und Normen, sondern machen Hoffnung auf Zukunft. Die Grundlage menschlicher Existenz ist demnach Beziehung, von deren Gestaltung die Zukunft abhängt.

Konkret erfahrbar und vorweggenommen wird die Wirklichkeit dieser $\mathrm{Zu}$ kunft bereits im gemeinsamen (liturgischen) Feiern. Form und Struktur der religiösen Feste und Feiern sorgen dafür, in dem es bestimmte Gestaltungs- und Teilnahmeregeln gibt, die soziale, kulturelle, politische und ökonomische Unterschiede für die Zeit des Feierns aufheben. Beim gemeinsamen Essen und Trinken steht die Erinnerung an die Zukunft im Zentrum: Man erinnert sich an die Verheißungen der Zukunft, an die Ereignisse der Vergangenheit und reinterpretiert in deren Licht die Gegenwart, in der die Zukunft als bereits angebrochen erfahrbar wird. Dies ist bis heute der innere Sinn religiöser Feiern im 
Judentum wie im Christentum: Sie erinnern, dass heute möglich wird, was für die Zukunft versprochen ist, weil es schon einmal so war. Dies stärkt die Hoffnung und Vertrauen auf Zukunft.

Die biblische „Große Erzählung“ ist also weder politisches Parteiprogramm noch spiritueller Sonderweg in den Himmel, sondern beschreibt konkrete Lebenserfahrungen, die im Horizont der Geschichte mit Gott gedeutet und bestanden werden. Bemerkenswert ist ihr Entstehungskontext: Flucht und Migration. Könnte sie nicht zuletzt deshalb heute weitergeschrieben werden?

Auch die gegenwärtigen Migrationen wären dann ein Beitrag zur Befreiungsgeschichte der Menschheit. Sie können zum Ort werden, an dem sich die Menschheit den Versprechungen und Verheißungen ein Stückweit nähert, ihre Einheit zu erkennen und in Verschiedenheit und Gerechtigkeit friedlich zusammenzuleben. Theologisch gesprochen: Ein Prozess, in dem Gott auf neue und vertiefte Weise begegnen könnte. Wie wirkt sich eine solche Sicht auf das Handeln, auf das aktuelle Zusammenleben oder politische Entscheidungen aus? Was bewirkt eine gegenteilige Sicht, die solche Deutungen als naiv betrachtet?

Eine Anleitung, wie eine solche Befreiungsgeschichte genau aussieht, ist in der Bibel nicht zu finden. Dazu bedarf es des Sachverstandes und der Kompetenz der Zeitgenossen, Experten, Politiker, Ökonomen usw. Die biblische „Große Erzählung" ermutigt und bestärkt jedoch Migranten und Flüchtlinge in ihrer Hoffnung auf ein besseres Leben, die sie aufbrechen lässt. Sie ermutigt und bestärkt die sesshaften Europäer, sich auf eine neue geschichtliche Situation einzulassen und mit den Flüchtlingen und Migranten gemeinsam aufzubrechen, die Zukunft zu gestalten. Befreit werden könnten beide: Die Ankommenden von Armut, Diskriminierung und Ausschluss; die Einheimischen von ihren Ängsten und Lebenseinschränkungen; beide von Stammes- und Rudelmentalitäten hin zu einem Zusammenleben in lebendigen, weil vielfältigen Gemeinschaften.

Umkehr wäre dazu freilich erforderlich: Der Abschied Europas von hegemonialen Politiken, das Teilen von Ressourcen und Macht, die Reue über eigene, menschenfeindliche Lebensweisen in Geschichte und Gegenwart hin zu gerechteren, humaneren Lebensweisen und Strukturen in Politik und Ökonomie. Entscheidend aus biblischer Sicht sind dabei die Beziehungen zu den Migranten, denen eine zentrale Rolle in dieser Geschichte zukommt.

Theologisch gesprochen: Auf diese Weise könnten die Migrationen der Gegenwart zu einem „Instrument“ der Heilsgeschichte Gottes mit seiner Menschheit werden, der durch Migration geholfen wird, ein Stückweit mehr zusammenzuwachsen.

Naiv?

Das Lehramt der Katholischen Kirche denkt jedenfalls genau in diese Richtung, wenn es sowohl die Übel im Kontext der Migrationen benennt und diese zugleich als möglichen Ort der Gnade erkennt. So wird das Phänomen der Migration als „ein beredtes Zeugnis der sozialen, ökonomischen und demographischen Ungleichgewichte sowohl auf regionaler wie auf weltweiter Ebene, die den 
Anstoß zur Emigration geben“ ${ }^{“ 105}$ gesehen. Als Ursachen werden „übertriebener Nationalismus, in vielen Ländern geradezu [...] Hass gegen Bevölkerungsminderheiten oder Gläubige von religiösen Minderheiten, die systematische oder gewaltsame Marginalisierung derselben sowie [...] in bürgerlichen, politischen, ethnischen und sogar religiöse Konflikten, die alle Kontinente mit Blut überziehen“106 genannt. Zur Frage stellt das kirchliche Lehramt daher „die Frage nach einer neuen internationalen Wirtschaftsordnung für eine gerechtere Verteilung der Güter der Erde“, sowie „die Notwendigkeit eines wirksameren Einsatzes zur Realisierung von Bildungs- und Pastoralsystemen im Hinblick auf eine Erziehung zu einer ,mondialen Sicht', das heißt zu einer Sicht der Weltgemeinschaft, die als eine Familie von Völkern angesehen wird, der schließlich im Blick auf das universale Gemeinwohl die Güter der Erde zustehen “107. In eben diesen Ansprüchen erkennt die Instruktion Erga migrantes aber zugleich einen Zuspruch Gottes: „Der Übergang von monokulturellen zu multikulturellen Gesellschaften kann sich so als Zeichen der lebendigen Gegenwart Gottes in der Geschichte und in der Gemeinschaft der Menschen erweisen, da er eine günstige Gelegenheit bietet, den Plan Gottes einer universalen Gemeinschaft zu verwirklichen.“108

\subsubsection{Ethos: Mittel gegen Angst und „Frühwarnsystem“}

Ein wesentliches Element der Bibel ist deren Ethos, das im Alten wie im Neuen Testament um die Frage eines gerechten Zusammenlebens von freien Menschen in all ihrer Verschiedenheit kreist. Dieses Ethos hat - bei aller Verschiedenheit der konkreten Ethiken - eine eindeutige Option für jene, die unsichtbar, marginalisiert, arm und ausgeschlossen sind.

Im Wesentlichen bearbeitet es die beiden großen „Beziehungsstörungen“ der Menschen: zum einen die Neigung des Menschen, sich „Götzen“ zu schaffen, d.h. irdische Wirklichkeiten - Personen, Menschen, Werte, Ideen - absolut zu setzen und sich ihnen zu unterwerfen; zum anderen die Zerstörung menschlicher Sozialbeziehungen. Ob Gesetzesbücher, Ver- und Gebote im Alten Testament, die Bergpredigt (Mt 5) oder die Gerichtsrede Jesu (Mt 25): Entwickelt wird ein Ethos, das Menschen unterstützen soll, in Freiheit ihr Zusammenleben in der Geschichte zu gestalten und dabei das Leben zu schützen und zu fördern. Dieses Ethos ermöglicht Freiheit - und setzt sie zugleich voraus (vgl. Ex 20; Dtn 5), damit Regeln und Gebote nicht erneut zum Unterwerfungsmittel werden.

Insofern bietet das Ethos auch ein „Mittel“ gegen die Angst, die die Freiheit mit sich bringt. Es schützt den Einzelnen, Sozialbeziehungen und die Gemeinschaft $-\mathrm{d}$.h. Menschen vor sich selbst und voreinander; und eröffnet zugleich

105 Siehe Internetquellen: Päpstlicher Rat der Seelsorge für die Migranten und Menschen unterwegs: Instruktion Erga migrantes caritas Christi 1.

106 Ebd., 8.

107 Ebd.

108 Ebd., 9. 
Freiräume, sich den Aufgaben der Geschichte zu stellen. Natürlich sind die damit verbundenen Regeln und Normen im Kontext konkreter Situationen auszulegen und weiterzuentwickeln, wie es ja auch in der Schrift und in den diesen nachfolgenden Auslegungstraditionen in Judentum wie Christentum zu beobachten ist. Wichtig ist das Anliegen: Freiheitssicherung und -ermöglichung, Beziehungsschutz und -förderung.

Dieses Ethos ließe sich auch als „Frühwarnsystem“ betrachten, auf das man in Krisenzeiten zurückgreifen könnte. Entstanden in der Reflexion von Katastrophen lässt sich quasi ex negativo rekonstruieren, worin die Verfasser die fundamentalen Bedrohungen des Lebens und des Zusammenlebens von Menschen erkannt haben. Es wird dabei durchaus realistisch mit der Neigung des Menschen zum Bösen gerechnet, die in ihrer Wirkmacht gebannt und zivilisiert werden soll: der Sünde als fundamentaler Beziehungsstörung soll Einhalt geboten werden. Weil die Verfasser der Schrift über ausreichend historische Erfahrung verfügen, lernen sie zu erkennen, welches Verhalten bzw. welche Sozialordnungen das Leben und Zusammenleben von Menschen bedrohen. So führen ein zu großes Ausmaß an sozialer und ökonomischer Ungleichheit ebenso zu politischen Katastrophen wie der Verlust der Gottesbeziehung. Dem soll nicht nur, dem kann vorgebeugt werden.

Erneut wird der migratorische Entstehungskontext sichtbar. Denn die Verantwortung für Arme und Fremde spielt eine Schlüsselrolle in der Vorsorge. Werden diese sozial als besonders vulnerabel erkannten Gruppen vernachlässigt, gibt es gute Gründe für die Angst. Es drohen der Zusammenbruch der sozialen Ordnung und politische Katastrophen: nicht zuletzt Migrationen. Denn die Armen und Fremden werden um ihr Leben zu kämpfen beginnen (Exodus) und die herrschende Ordnung zum Einsturz bringen. Theologisch gesprochen: Gott steht auf deren Seite und „stürzt die Mächtigen vom Thron“ (Lk 1,52).

Diese Dynamiken, die bereits in biblischen Texten reflektiert werden, haben sich in der Menschheitsgeschichte immer wieder wiederholt. Wäre eine Reinterpretation des biblischen Ethos im Migrationskontext der Gegenwart nicht auch ein heilsames Mittel gegen Angst und eine hervorragende Zukunftsvorsorge? In der Katholischen Soziallehre, der christlichen Sozialethik und der lehramtlichen Migrationstheologie werden dafür schon längst Modelle entwickelt. ${ }^{109}$

\subsubsection{Reich Gottes: Zusammenleben}

Im Zentrum des Evangeliums des Jesus von Nazareth steht die Nachricht von Ankunft und Anbruch der Gottesherrschaft, die im Bild des „Reiches Gottes“ beschrieben wird (Mk 1,15). ${ }^{110}$ Dieses „Reich Gottes“ beschreibt Begründung und Beginn einer neuen Form menschlichen Zusammenlebens. Jesus von Naza-

109 Z.B. Becka / Rethmann 2010; Cassee / Goppel 2012; Heimbach-Steins 2016.

110 Zum folgenden ausführlich: Polak / Jäggle 2014, S. 603-638; Eigenmann 1998. 
reth stellt mit diesem Bild jenes Element in die Mitte seiner Verkündigung und Praxis, das das Alte Testament als jenen Lebensraum beschreibt, in dem Menschen leben, leben können und sollen. Das „Reich Gottes“ beschreibt eine neue, veränderte Lebensweise und Sozialordnung: individuell und sozial; innerlich und äußerlich; spirituell und politisch. In und mit seinem Leben, Sterben und Auferstehen legt Jesus in Wort und Tat diese Erfahrung des Reiches Gottes, von der insbesondere die Thora durchdrungen ist, aus. Menschen werden geheilt und von Dämonen befreit: von ihren Ängsten, Besessenheiten und Zwängen, ihren Lebenseinschränkungen, ihren Traumata und ihrer Trauer. Es gibt keine Generallösung für alle, sondern jeder Einzelne steht mit seiner Geschichte im Zentrum des Handelns Gottes. Das Reich Gottes ,verkehrt“ die üblichen sozialen, ökonomischen und politischen Ordnungen, indem laterale und vertikale Ordnungen umgekehrt werden. Arme, Ausgeschlossene, Fremde werden einbezogen, Frauen und Kinder in die Mitte gestellt, Reichtum dient dem Gemeinwohl, politische Macht den Ohnmächtigen. In alledem erneuert sich auch die Beziehung zu Gott. Diese neue Lebensweise, die neue Ordnung erfüllt mit Freude. Sie entspringt dem gemeinsamen Feiern und mündet in dieses.

Jesus von Nazareth stellt dabei - vor allem in seinen Gleichnissen - den Alltag der „kleinen Leute“ ins Zentrum. In deren Alltag ist dieses Reich Gottes in besonderer Weise erfahrbar. Wenn Menschen gemeinsam feiern und beten, wenn sie geheilt werden und umkehren, wenn sich die Ordnungen der Macht und des Reichtums verändern und Leben fördern. Freilich geschieht dies nur phasenweise und fragmentarisch. Aber dort, wo es geschieht, ist das Reich Gottes jetzt schon ganz präsent - wenn man es wahrnehmen kann und will.

Die Wirklichkeit des „Reiches Gottes“, wie sie eben skizziert wurde, kann auch ein verändertes Licht auf Flucht und Migration werden. Biblisch betrachtet, ereignet es sich überall dort, wo sich Menschen auf das Zusammenleben mit Migrantinnen und Flüchtlingen einlassen; wo sie sich für die Transformation politischer oder ökonomischer Verhältnisse einsetzen, um Gleichheit, Gerechtigkeit und Teilhabe zu fördern; wo im Leben mit und Lernen von Flüchtlingen und Migranten die Frage nach Gott neu gestellt wird. Dies alles geschieht bereits, wie beschrieben, innerhalb und außerhalb der Kirchen. Die Botschaft vom Reich Gottes ist eine Zusage, die sich heute schon konkret zeigt, und bleibt zugleich Zumutung und Orientierung für das konkrete Handeln.

Wie bei allen bibeltheologischen Erfahrungen handelt es sich nicht um Ideen oder Theorien, sondern praktische Beziehungserfahrungen. Deren Wahrheit bewahrheitet und bewährt sich, indem sie getan wird. Biblische „Wahrheit" hat einen besonderen epistemologischen Charakter, denn es werden keine Ideen umgesetzt, sondern die Praxis generiert neue Einsichten. Die Migrationen der Gegenwart sind eine ausgezeichnete Gelegenheit, aus der Beobachterrolle - auch der theologischen - auszusteigen und sich auf jene, die da ankommen, einzulassen - und solcherart die Migrations,,theologien“ der Schrift zu überprüfen, weiterzuentwickeln und die Geschichte der Migrationen weiterzuschreiben. 


\section{Abschluss}

Weder der christliche Glaube als „Weltanschauung“ noch eine Theologie, die Lehren verkündet, helfen gegen Angst und Trauer noch stiften sie als solche Freude und Hoffnung. Patentrezepte oder Lösungsgarantien für die anstehenden Herausforderungen globalen Ausmaßes kann auch der hier entwickelte Ansatz nicht bieten.

Wohl aber hoffe ich, nachvollziehbar gemacht zu haben, worin der Beitrag eines praktisch-theologischen Zugangs bestehen könnte. Eine theologische Sicht ermöglicht eine geistige, inhaltlich begründete Transformation von Angst, ermutigt zur Trauer und entwickelt Wahrnehmungen, Deutung und Handlungsprinzipien, die Hoffnung und Freude wachsen lassen können. Der ethische Monotheismus, wie ihn die biblische Tradition bezeugt, ermutigt dazu, sich auf die konkrete Geschichte einzulassen und sich ihr anzuvertrauen. Flüchtlinge und Migranten haben einen Namen, ein Gesicht, eine Geschichte. Sich auf Beziehungen und Zusammenleben mit ihnen einzulassen, kann Kreativität freisetzen, um soziale, politische und ökonomische Lösungen zu suchen, die allen zugutekommen. Das Zusammenleben mit ihnen und der gemeinsame Einsatz können zur Entwicklung einer menschlicheren Gesellschaft führen. Dies ist ein probates „Mittel“ gegen die apokalyptischen Ängste unserer Zeit.

Um dieses Potential freizulegen, braucht es freilich ein spezifisches Profil der Theologie. Wie müsste nun eine Theologie aussehen, die dazu beiträgt, Trauer und Angst im Horizont von Flucht und Migration in Freude und Hoffnung zu verwandeln? Eine solche Theologie hat allem voran eine andere als die traditionell thetisch-theoretische Sprache. Ihre Sprache ist dialogisch und relational, d.h. sie drückt sich nicht ausschließlich im klassischen Vokabular aus, sondern lässt erkennen, dass sie mit konkreten Menschen im Gespräch ist und von ihnen lernt. Sprache und Erfahrungen von Menschen kommen darin zur Sprache. Eine solche Theologie ist demnach auch narrativ. Sie erzählt und hat „empirische“ Anteile. Gefühle, Fragen, Zweifel, Erfahrungen von Leid, Schmerz, Schuld und Glück, usw. kommen konkret zur Sprache. Eine solche Theologie „weiß“ nicht immer schon alles, sondern „denkt“ laut nach im Sinne Hannah Arendts: Sie fragt, zweifelt, unterscheidet. Sie unterstützt bei der Reflexion und Entscheidungsfindung und ermutigt zum Handeln. Sie stellt dafür Sprache zur Verfügung: Fragen, Erfahrungen, Kriterien, Narrative. Insofern ist eine solche Theologie eine spirituelle Theologie: Sie verschränkt Praxis, Denken und Erfahrung und erschließt deren Sinn im Licht und in der kritischen Auseinandersetzung mit der biblischen und kirchlichen Tradition. Eine solche Theologie spricht daher weniger „über“ Gott oder bietet Gottesvorstellungen an, sondern trägt dazu bei, dass Menschen eine Beziehung zu Gott aufbauen können. Eine solche Theologie ist zugleich ,politisch“, d. h. sie denkt die Erfahrungen der Einzelnen immer auch im Horizont der „Zeichen der Zeit“ und deren sozialer, politischer und historischer Dimensionen. Sie thematisiert die menschlichen Grundstimmungen auf der Basis 
einer Anthropologie, die den Menschen als relationales und gemeinschaftsbezogenes Wesen versteht, das für ein gerechtes Gemeinwohl mitverantwortlich ist. Für die spirituelle wie politische Dimension solcher Theologie ist es notwendig, die der biblischen und kirchlichen Tradition zugrundeliegenden Erfahrungen freizulegen und mit jenen der Gegenwart in ein einander wechselseitig erschließendes Gespräch zu bringen. Auf diese Weise, in der Verschränkung von spiritueller und politischer Erfahrung von Gegenwart und Vergangenheit, nimmt sie durch die Art ihrer erzählerischen Sprache Menschen in einen Prozess hinein, in dem Transformation von Gefühlen und Stimmungen möglich werden kann. Neben einer dafür erforderlichen, erfahrungsgesättigten und reflektierten spirituell-politischen Kompetenz des Theologisierenden braucht es dafür selbstverständlich auch jede Menge Fach- und Sachkenntnisse. Diese sollen die Stimmungen der Menschen aber eben nicht weg-, herbei oder schönreden und beseitigen, sondern stehen im Dienste ihrer Transformation. Für das hier behandelte Thema bedeutet dies: Eine Theologie der Migration, die bei den Freuden und Ängsten, bei Trauer und Angst der Menschen ansetzt, muss „,ins Feld“. Ohne konkretes Zusammenleben und Beziehung zu Flüchtlingen und MigrantInnen, aber auch zu den Menschen der Mehrheitsgesellschaft, die von Migration betroffen sind, und seien es rassistisch eingestellte Menschen, gibt es weder eine Theologie der Migration noch eine Transformation durch eine solche. Der „Migrationstheologe" muss in gewisser Weise selbst ein Migrant, eine Migrantin zwischen den Welten sein und Transformation seiner eigenen Stimmungen sowie seine Erfahrungen in dieser Wirklichkeit durchlitten, durchlebt und kritisch reflektiert haben. Wie jede substantielle Theologie ist auch eine transformative „Migrationstheologie“ keine (schein-)-objektive Theorie „über" Flucht und Migration. Wissenschaftlich wird sie durch die nachvollziehbare Kohärenz und Konsistenz ihrer Argumentation.

Muss man dazu an Gott glauben? Praktisch-theologisch gesehen, beginnt sich der christliche Glaube bereits zu vollziehen, in dem man sich auf die hier beschriebenen Prozesse einlässt und bereit ist, Flucht und Migration aus einer hoffnungsgeleiteten Sicht wahrzunehmen. Die Praxis, die daraus erfolgt - ob individuell oder kollektiv, sozial, kulturell, politisch oder ökonomisch - setzt sich der Offenheit der Geschichte aus und damit unvorhersehbare Dynamiken des Guten frei. Die biblische Praxis ist eine Hoffnungs-Praxis.

Wer dabei explizit an Gott glaubt, d.h. sich von einer Gottesbeziehung getragen weiß, wird sich mit meinen Überlegungen wohl leichter tun. Für notwendig im Sinne eines Bekenntnisses oder des Glaubens „an“ bestimmte Gottesvorstellungen halte ich eine solche explizite Beziehung nicht. Der Versuch der geistigen Transformation in Bezug auf eine differenzierte, problembewusste und zugleich „chancenorientierte“ Wahrnehmung von Flucht und Migration und die Orientierung am soziopolitischen Ethos, wie es die Heilige Schrift entwirft, hat eine humanisierende Eigendynamik. 
Der Apostel Paulus spricht im Römerbrief von den Geburtswehen einer neuen Menschheit (Röm 8,22) - sein Bild für eine Theologie der Geschichte. In diesem Zusammenhang wird auch die Bedeutung der Hoffnung erwähnt (Röm 8,20.24). Einer solchen Hoffnung bedarf jede Gebärende, denn Geburten können - im Westen vergessen - lebensgefährlich sein. Um ein Kind zu gebären, braucht man keinen Glauben an Gott im klassischen Sinn, wohl aber Hoffnung und Mut. Es als Gottesgeschenk zu betrachten, obliegt der Freiheit des Einzelnen. Geboren wird das Kind - hoffentlich - so oder so.

Kündigt sich mit den Migrationen der Gegenwart eine weitere Wehe der Geburt einer neuen Menschheit an? Ich hoffe dies.

\section{Literaturverzeichnis}

Arendt, Hannah: Vom Leben des Geistes. Das Denken. Das Wollen. Zürich ${ }^{2} 2002$.

Arendt, Hannah: Vita activa oder Vom tätigen Leben. München ${ }^{2} 1981$.

Assmann, Jan: Exodus. Die Revolution der Alten Welt. München 2015.

Atac, Ilker / Rosenberger, Sieglinde (Hg.): Politik der Inklusion und Exklusion. Wien 2013.

Becka, Michelle / Rethmann, Albert-Peter (Hg.): Ethik und Migration-Gesellschaftliche Herausforderungen und sozialethische Reflexion. Paderborn / München / Wien 2010.

Bergolte, Michael: Christen, Juden, Muselmanen. Die Erben der Antike und der Aufstieg des Abendlandes 300-1400 n. Chr. München 2006.

Blom, Philipp: Die zerrissenen Jahre: 1918-1938. München 2014.

Blom, Philipp: Der taumelnde Kontinent. Europa 1900-1914. München 2009.

Braulik, Georg: „Eine Gesellschaft ohne Arme. Das altorientalische Armenethos und die biblische Vision“, in: IKaZ Communio (44) 2015, S. 563-576.

Brunner, Markus: „Die Kryptisierung des Nationalsozialismus“, in: Brunner, Markus / Lohl, Jan / Pohl, Rolf / Winter, Sebastian (Hg.): Volksgemeinschaft, Täterschaft und Antisemitismus. Beiträge zur psychoanalytischen Sozialpsychologie des Nationalsozialismus und seiner Nachwirkungen. Gießen 2011, S. 169-194.

Brunner, Markus / Lohl, Jan / Pohl, Rolf / Winter, Sebastian (Hg.): Volksgemeinschaft, Täterschaft und Antisemitismus. Beiträge zur psychoanalytischen Sozialpsychologie des Nationalsozialismus und seiner Nachwirkungen. Gießen 2011.

Bude, Heinz: Gesellschaft der Angst. Hamburg 2014.

Cassee, Andreas / Goppel, Anna (Hg.): Migration und Ethik. Münster 2012.

Castles, Stephen / Miller, Mark: The Age of Migration: International Population Movements in the Modern World. 3rd, revised, and updated edition. New York 2003.

Certeau, Michel de: Mystische Fabel. 16. - 17. Jahrhundert. Berlin 2010.

Cohen, Robin (Hg.): The Cambridge survey of World migration. Cambridge 1995.

Decker, Oliver / Kiess, Johannes / Brähler, Elmar: Die stabilisierte Mitte. Rechtsextreme Einstellung in Deutschland 2014. Leipzig 2014.

Drewermann, Eugen: Strukturen des Bösen. Die jahwistische Urgeschichte in philosophischer Sicht. München 1977. 
Ebach, Jürgen: „Globalisierung - Rettung der Vielfalt. Die Erzählung vom ,Turmbau zu Babel' im aktuellen Kontext", in: Hartmut Schröter (Hg.): Weltentfremdung, Weltoffenheit, Alternativen der Moderne: Perspektiven aus Wissenschaft-Religion-Kunst. Münster 2008, S. 39-58.

Eigenmann, Urs: Das Reich Gottes und seine Gerechtigkeit für die Erde. Die andere Vision vom Leben. Luzern 1998.

Flusser, Vilém: Von der Freiheit des Migranten. Einsprüche gegen den Nationalismus. Berlin 1992.

Foucault, Michel / Pearson, James (Hg.): Diskurs und Wahrheit: Die Problematisierung der Parrhesia. Sechs Vorlesungen, gehalten im Herbst 1983 an der Universität von Berkeley/Kalifornien. Berlin 1996.

Fratscher, Marcel: Verteilungskampf. Warum Deutschland immer ungleicher wird. München 2016.

Geulen, Christian: Geschichte des Rassismus. München 2014.

Heidegger, Martin: Sein und Zeit (= Gesamtausgabe Band 2). Frankfurt am Main 1977.

Heimbach-Steins, Marianne: Grenzverläufe gesellschaftlicher Gerechtigkeit. MigrationZugehörigkeit - Beteiligung. Paderborn 2016.

Heitmeyer, Wilhelm: Deutsche Zustände (10 Bände). Berlin 2002-2012.

Holtkamp, Jürgen: Flüchtlinge und Asyl. Regensburg 2016.

Illouz, Eva: Israel. Berlin 2015.

Khosrokhavar, Farhad: L' Islam de Jeunes. Paris 1997.

Lapide, Pinchas: Auferstehung - ein jüdisches Glaubenserlebnis. Berlin 2010 [Nachdruck der Erstausgabe von 1977].

Livi Bacci, Massimo: Kurze Geschichte der Migration. Berlin 2015.

Manemann, Jürgen: Der Dschihad und der Nihilismus des Westens. Warum ziehen junge Europäer in den Krieg? Bielefeld 2015.

Marx, Karl / Engels, Friedrich: „Der achtzehnte Brumaire des Louis Bonaparte“, in: Institut für Marxismus-Leninismus / Sozialistische Einheitspartei Deutschlands (Hg.): Werke 8. Berlin 1972, S. 115-123.

Moïsi, Dominique: Kampf der Emotionen. Wie Kulturen der Angst, Demütigung und Hoffnung die Weltpolitik bestimmen. München 2009.

Naprushkina, Marina: Neue Heimat? Wie Flüchtlinge uns zu besseren Menschen machen. München 2015.

Nussbaum, Martha: Die neue religiöse Intoleranz. Ein Ausweg aus der Politik der Angst. Darmstadt 2014a.

Nussbaum, Martha: Politische Emotionen. Warum Liebe für Gerechtigkeit wichtig ist. Berlin 2014b.

Pock, Johann / Feeser-Lichtenfeld, Ulrich (Hg.): Trauerrede in postmoderner Trauerkultur (= Werkstatt Theologie 18). Berlin 2011.

Polak, Regina: „An den Grenzen des Faches“, in: PThI (2) 2015a, S. 83-88, verfügbar unter: http://nbn-resolving.de/urn:nbn:de:hbz:6:3-pthi-2015-16316 [15.04.2016].

Polak, Regina: „Migration as ,Sign of the Times‘. Perspectives from Practical Theology“, in: Gruber, Judith / Rettenbacher, Sigrid (Hg.): Migration as a Sign of the Times. Leiden 2015b, S. 47-78.

Polak, Regina: „Migration als Ort der Theologie“, in: Keßler, Tobias (Hg.): Migration als Ort der Theologie (= Weltkirche und Mission 4). Regensburg 2014a, S. 87-114. 
Polak, Regina: „Migration als Heimkehr zu Gott und seiner Lebensordnung. Die Bibel als Migrationsbuch“, in: Religion im Wandel. Transformationsprozesse religiöser Gemeinschaften in Europa durch Migration - Interdisziplinäre Perspektiven (= Religion and Transformation in Contemporary European Society 9). Wien 2014b, S. 5 10.

Polak, Regina: „Migration und Katholizität“, in: Polak, Regina / Reiss, Wolfram (Hg.): Religion im Wandel. Transformationsprozesse religiöser Gemeinschaften in Europa durch Migration - Interdisziplinäre Perspektiven (= Religion and Transformation in Contemporary European Society 9). Wien 2014b, S. 233-296.

Polak, Regina: „Perspektiven einer migrationssensiblen Theologie“, in: Dahlvik, Julia / Fassmann, Heinz / Sievers, Wiebke (Hg.): Migration und Integration - wissenschaftliche Perspektiven aus Österreich (= Jahrbuch für Migrations- und Integrationsforschung in Österreich 2). Wien 2013, S. 195-214.

Polak, Regina / Jäggle, Martin: „Diversität und Convivenz: Miteinander Lebensräume gestalten - Miteinander Lernprozesse in Gang setzen“, in: Schinkele, Brigitte / Kuppe, René / Schima, Stefan / Synek, Eva M. / Wallner, Jürgen / Wieshaider, Wolfgang (Hg.): Recht Religion Kultur. Festschrift für Richard Potz zum 70. Geburtstag. Wien 2014, S. 603-638.

Polak, Regina / Jäggle, Martin: „Gegenwart als locus theologicus. Für eine migrationssensible Theologie im Anschluss an Gaudium et spes“, in: Tück, Jan-Heiner (Hg.): Erinnerung an die Zukunft. Das Zweite Vatikanische Konzil. Freiburg / Basel / Wien 2012, S. 570-598.

Polanyi, Karl: The Great Transformation. Politische und ökonomische Ursprünge von Gesellschaften und Wirtschaftssystemen. Stuttgart ${ }^{2} 1990$.

Rosenberger, Sieglinde / Seeber, Gilg: „Lokale Politik und Zivilgesellschaft. Notizen zur OÖ-Wahl“, in: KSOE-Nachrichten (1) 2016.

Rosenberger, Sieglinde / Seeber, Gilg: „Kritische Einstellungen: BürgerInnen zu Demokratie, Politik, Migration“, in: Polak, Regina (Hg.): Zukunft. Werte. Europa. Die Europäische Wertestudie 1990-2010: Österreich im Vergleich. Wien 2011, S. 165-190.

Sander, Hans-Joachim: „Ein Ortswechsel des Evangeliums - die Heterotopien der Zeichen der Zeit", in: Hünermann, Peter / Hilberath, Bernd-Jochen (Hg.): Herders Theologischer Kommentar zum Zweiten Vatikanischen Konzil (Band 5). Freiburg im Breisgau 2006, S. 434-445.

Sander, Hans-Joachim: „,Ihr liebt das Leben und wir lieben den Tod“ - das Problem gewaltbereiter religiöser Identifizierungen mit Gott“, in: ThPQ (153) 2005, S. 115124.

Sander, Hans-Joachim: „Die Entdeckung des Evangeliums in den Konflikten der Gegenwart“, in: Fuchs, Gotthard / Lienkamp, Andreas (Hg.): 30 Jahre Pastoralkonstitution „Die Kirche in der Welt von heute“. Münster 1997, S. 85-102.

Sassen, Saskia: Ausgrenzungen. Brutalität und Komplexität in der globalen Wirtschaft. Frankfurt am Main 2015.

Saunders, Doug: Arrival City. München 2011 [2009].

Schiffauer, Werner: Parallelgesellschaften. Wie viel Wertekonsens braucht unsere Gesellschaft? Für eine kluge Politik der Differenz. Bielefeld 2008. 
Schwienhorst-Schönberger, Ludger: „,... denn Fremde seid Ihr gewesen im Lande Ägypten'. Zur sozialen und rechtlichen Stellung von Fremden und Ausländern im alten Israel“, in: BLit (63) 1990, S. 108-117.

Shulamit Bruckstein, Almut: Die Maske des Moses. Studien zur jüdischen Hermeneutik. Berlin ${ }^{2} 2007$.

Standing, Guy: The Precariat. The new dangerous class. London / New York 2011.

Strube, Sonja Angelika (Hg.): Rechtsextremismus als Herausforderung für die Theologie. Freiburg im Breisgau 2015.

Todorov, Tzvetan: Die Angst vor den Barbaren. Kultureller Vielfalt versus Kampf der Kulturen. Hamburg 2010.

Tomasi, Silvano: „Migration und Katholizismus im globalen Kontext“, in: Concilium (44/ 5) 2008, S. 520-537.

Tomka, Miklós / Szilárdi, Réka: Religion and Nation. unveröff. Manuskript, i. E. 2016. Trojanow, Ilija: „Migration über den Gartenzaun“, in: Sperl, Gerfried (Hg.): Flüchtlinge. Wien 2016, S. 11-14.

Welzer, Harald: Täter. Wie aus ganz normalen Menschen Massenmörder werden. Frankfurt am Main 2007.

Welzer, Harald / Moller, Sabine / Tschuggnall, Karoline: „Opa war kein Nazi“. Nationalsozialismus und Holocaust im Familiengedächtnis. Frankfurt am Main 2002.

Winkler, Beate: Unsere Chance. Mut, Handeln und Visionen in der Krise. Berlin 2015.

Verkaamp, Ton: Die Welt anders. Politische Geschichte der Großen Erzählung. Hamburg 2012.

Zulehner, Paul: Entängstigt euch! Die Flüchtlinge und das christliche Abendland. Ostfildern 2016.

\section{Internetquellen}

Bayrakli', Enes / Hafez, Farid (Hg.): European Islamophobia Report. Istanbul 2015, verfügbar unter: http://www.islamophobiaeurope.com [15.04.2016].

Bertelsman-Stiftung: Wirtschafts- und Schuldenkrise der EU: Kinder und Jugendliche sind die großen Verlierer, verfügbar unter: https://www.bertelsmann-stiftung.de/de/ themen/aktuelle-meldungen/2015/oktober/wirtschafts-und-schuldenkrise-der-eu-kin der-und-jugendliche-sind-die-grossen-verlierer/ [15.04.2016].

Borderline-Europe: Menschenrechte ohne Grenzen, verfügbar unter: http://www.bor derline-europe.de [08.03.2016].

Deutsche Bischofskonferenz: Leitsätze des kirchlichen Engagements für Flüchtlinge, verfügbar unter: http://www.dbk.de/fileadmin/redaktion/diverse_downloads/presse_ 2016/2016-031-Anlage-1-Leitsaetze-FVV-Pressebericht.pdf [12.03.2016].

Documents of the Ecumenic Council: Ecumenical Documents on Migration, verfügbar unter: https://www.oikoumene.org/de/resources/documents/programmes/umer/mis sion-from-the-margins/migration/ecumenical-documents-on-migration [09.03.2016].

Europäische Agentur für Grundrechte (FRAU), verfügbar unter: http://fra.europa.eu/de [12.03.2016].

Ökumenischer Rat der Kirchen: Europas Reaktion auf die Flüchtlings- und Migrantenkrise, von den Ursprungsorten über die Durchgangsstationen bis zur Aufnahme 
und Zuflucht: ein Aufruf zu gemeinsamer Verantwortung und koordiniertem Handeln, verfügbar unter: https://www.oikoumene.org/de/resources/documents/pro grammes/umer/mission-from-the-margins/migration/europes-response-to-the-refuge -crisis [09.03.2016].

Forum gegen Antisemitismus: Jahresbericht 2015. Wien 2016, verfügbar unter: http:// www.fga-wien.at/de/ [15.04.2016].

„Franziskus entschuldigt sich bei Flüchtlingen“, in: Die Zeit, 19. 04. 2016, verfügbar unter: http://www.zeit.de/gesellschaft/zeitgeschehen/2016-04/papst-franziskus-fluechtlingeeu-entschuldigung [22.04.2016].

„Geschichten vom Helfen: Landkarte einer neuen Zivilgesellschaft“, bei: Ö1, verfügbar unter: http://oe1.orf.at/miteinander_geschichten [15.04.2016].

ICMC, verfügbar unter: http://www.icmc.net/about-us [09.03.2016].

Kermani, Navid: Über die Grenzen - Jacques Mourad und die Liebe in Syrien, verfügbar unter: http://www.friedenspreis-des-deutschen-buchhandels.de/819312/ [20.04.2016].

Kilian, Inga: „Osteuropäische Bischöfe und die Flüchtlingsfrage“, bei: Domradio, 10. 09. 2015, verfügbar unter: http://www.domradio.de/themen/fluechtlingshilfe/2015-09-10/ osteuropas-bischoefe-und-die-fluechtlingsfrage [20.04.2016].

Mcelwee, Joshua J.: „Catholicism can and must change, Francis forcefully tells Italian church gathering“, in: National Catholic Reporter, 10.11.2015, verfügbar unter: https://www.ncronline.org/news/vatican/catholicism-can-and-must-change-francisforcefully-tells-italian-church-gathering [06.03.2016].

Migration 2010, verfügbar unter: http://migration.ceceurope.org [09.03.2016].

Päpstliche Kommission: Päpstlicher Rat der Seelsorge für die Migranten und Menschen unterwegs, verfügbar unter: http://www.vatican.va/roman_curia/pontifical_councils/ migrants/documents/rc_pc_migrants_doc_2003038_profile_ge.html [09.03.2016]. Umgewandelt in: Päpstlicher Rat der Seelsorge für Migranten und Menschen unterwegs, verfügbar unter: http://www.vatican.va/roman_curia/pontifical_councils/mi grants/index_ge.htm [09.03.2016].

Pastorale Konstitution Gaudium et Spes. Über die Kirche in der Welt von Heute, verfügbar unter: http://www.vatican.va/archive/hist_councils/ii_vatican_council/docu ments/vat-ii_const_19651207_gaudium-et-spes_ge.html [13.10.2016].

Päpstlicher Rat der Seelsorge für die Migranten und Menschen unterwegs: Instruktion Erga migrantes caritas Christi, verfügbar unter: http://www.vatican.va/roman_curia/ pontifical_councils/migrants/documents/rc_pc_migrants_doc_20040514_erga-migran tes-caritas-christi_ge.html\#Das\%20Ph\%E4nomen \%20der\%20Migration \% 20in\% 20 der\%20Sicht\%20des\%20Glaubens [15.04.2016].

The Churches' Commission for Migrants, available at: http://www.ccme.be/who-we-are/ [09.06.2016].

„Ungarischer Bischof spricht von ,Invasion muslimischer Flüchtlinge““, in: FAZ, 8. 09. 2015, verfügbar unter: http://www.faz.net/aktuell/politik/fluechtlingskrise/kritik-anpapst-franziskus-ungarischer-bischof-spricht-von-invasion-muslimischer-fluechtlinge13790835.html [20.04.2016].

Vertrag über die Gründung der Europäischen Union in der Fassung des Vertrags von Lissabon, Artikel 2, verfügbar unter: http://eur-lex.europa.eu/legal-content/DE/ TXT/HTML/?uri=OJ:C:2010:083:FULL\&from $=$ de [11.10.2016]. 